\title{
Prophylactic antibiotics or G-CSF for the prevention of infections and improvement of survival in cancer patients undergoing chemotherapy (Review)
}

Herbst C, Naumann F, Kruse EB, Monsef I, Bohlius J, Schulz H, Engert A

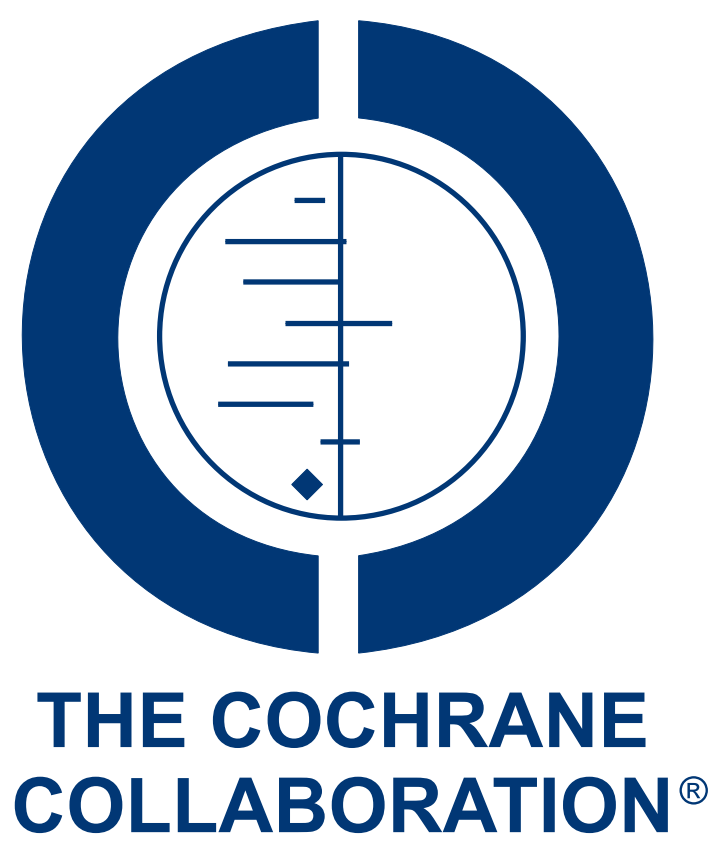

This is a reprint of a Cochrane review, prepared and maintained by The Cochrane Collaboration and published in The Cochrane Library 2009, Issue 1

http://www.thecochranelibrary.com

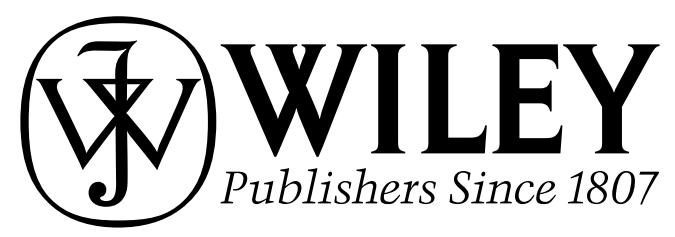

Prophylactic antibiotics or G-CSF for the prevention of infections and improvement of survival in cancer patients undergoing chemotherapy (Review)

Copyright $\odot 2009$ The Cochrane Collaboration. Published by John Wiley \& Sons, Ltd. 


\section{TABLE OF CONTENTS}

HEADER

ABSTRACT

PLAIN LANGUAGE SUMMARY

BACKGROUND

OBJECTIVES

METHODS

RESULTS

Figure 1.

DISCUSSION

AUTHORS' CONCLUSIONS . . . . . . . . . . . . . . . . . . . . . . . . . . . . . . . . 11

ACKNOWLEDGEMENTS . . . . . . . . . . . . . . . . . . . . . . . . . . . . . . . . . . . . . . . . . . . . 11

REFERENCES . . . . . . . . . . . . . . . . . . . . . . . . . . . . . . . . . . . . . . 11

CHARACTERISTICS OF STUDIES . . . . . . . . . . . . . . . . . . . . . . . . . . . . . . . . . . . 16

DATA AND ANALYSES . . . . . . . . . . . . . . . . . . . . . . . . . . . . . . . . . . . . . . . . . . . . . . . . .

APPENDICES . . . . . . . . . . . . . . . . . . . . . . . . . . . . . . . . . 20

HISTORY . . . . . . . . . . . . . . . . . . . . . . . . . . . . . . . . . . . . . . . 27

CONTRIBUTIONS OF AUTHORS . . . . . . . . . . . . . . . . . . . . . . . . . . . . . . . . . . . . . $\quad 27$

DECLARATIONS OF INTEREST . . . . . . . . . . . . . . . . . . . . . . . . . . . . . . . . 27

SOURCES OF SUPPORT . . . . . . . . . . . . . . . . . . . . . . . . . . . . . . . . . . . . . . . . . . . . . .

Prophylactic antibiotics or G-CSF for the prevention of infections and improvement of survival in cancer patients undergoing 


\title{
[Intervention Review]
}

\section{Prophylactic antibiotics or G-CSF for the prevention of infections and improvement of survival in cancer patients undergoing chemotherapy}

\author{
Christine Herbst $^{1}$, Frauke Naumann ${ }^{2}$, Eva-Brigitta Kruse ${ }^{3}$, Ina Monsef ${ }^{1}$, Julia Bohlius ${ }^{4}$, Holger Schulz ${ }^{1}$, Andreas Engert ${ }^{1}$ \\ ${ }^{1}$ Cochrane Haematological Malignancies Group, Department I of Internal Medicine, University Hospital of Cologne, Cologne, \\ Germany. ${ }^{2}$ Federal Institute for Drugs and Medical Devices (BfArM), Bonn, Germany. ${ }^{3}$ Beratungszentrum für Hygiene, Freiburg, \\ Germany. ${ }^{4}$ Institute of Social and Preventive Medicine, University of Bern, Bern, Switzerland \\ Contact address: Christine Herbst, Cochrane Haematological Malignancies Group, Department I of Internal Medicine, University \\ Hospital of Cologne, Kerpener Str. 62, Cologne, 50924, Germany. christine.herbst@uk-koeln.de. (Editorial group: Cochrane Haema- \\ tological Malignancies Group.)
}

Cochrane Database of Systematic Reviews, Issue 1, 2009 (Status in this issue: New) Copyright (C) 2009 The Cochrane Collaboration. Published by John Wiley \& Sons, Ltd.

DOI: $10.1002 / 14651858 . C D 007107 . p u b 2$

This version first published online: 21 January 2009 in Issue 1, 2009.

Last assessed as up-to-date: 2 September 2008. (Help document - Dates and Statuses explained)

This record should be cited as: Herbst C, Naumann F, Kruse EB, Monsef I, Bohlius J, Schulz H, Engert A. Prophylactic antibiotics or G-CSF for the prevention of infections and improvement of survival in cancer patients undergoing chemotherapy. Cochrane Database of Systematic Reviews 2009, Issue 1. Art. No.: CD007107. DOI: 10.1002/14651858.CD007107.pub2.

\begin{abstract}
A B S T R A C T
Background

Febrile neutropenia (FN) and other infectious complications are some of the most serious treatment-related toxicities of chemotherapy for cancer, with a mortality rate of $2 \%$ to $21 \%$. The two main types of prophylactic regimens are granulocyte (G-CSF) or granulocytemacrophage colony stimulating factors (GM-CSF); and antibiotics, frequently quinolones or cotrimoxazole. Important current guidelines recommend the use of colony stimulating factors when the risk of febrile neutropenia is above $20 \%$ but they do not mention the use of antibiotics. However, both regimens have been shown to reduce the incidence of infections. Since no systematic review has compared the two regimens, a systematic review was undertaken.
\end{abstract}

\section{Objectives}

To compare the effectiveness of G-CSF or GM-CSF with antibiotics in cancer patients receiving myeloablative chemotherapy with respect to preventing fever, febrile neutropenia, infection, infection-related mortality, early mortality and improving quality of life.

\section{Search strategy}

We searched The Cochrane Library, MEDLINE, EMBASE, databases of ongoing trials, and conference proceedings of the American Society of Clinical Oncology and the American Society of Hematology (1980 to 2007). We planned to include both full-text and abstract publications.

\section{Selection criteria}

Randomised controlled trials comparing prophylaxis with G-CSF or GM-CSF versus antibiotics in cancer patients of all ages receiving chemotherapy or bone marrow or stem cell transplantation were included for review. Both study arms had to receive identical chemotherapy regimes and other supportive care.

Data collection and analysis

Prophylactic antibiotics or G-CSF for the prevention of infections and improvement of survival in cancer patients undergoing chemotherapy (Review)

Copyright $\odot 2009$ The Cochrane Collaboration. Published by John Wiley \& Sons, Ltd. 
Trial eligibility and quality assessment, data extraction and analysis were done in duplicate. Authors were contacted to obtain missing data.

\section{Main results}

We included two eligible randomised controlled trials with 195 patients. Due to differences in the outcomes reported, the trials could not be pooled for meta-analysis. Both trials showed non-significant results favouring antibiotics for the prevention of fever or hospitalisation for febrile neutropenia.

\section{Authors' conclusions}

There is no evidence for or against antibiotics compared to G(M)-CSFs for the prevention of infections in cancer patients.

\section{PLAIN LANGUAGE SUMMARY}

Prophylactic antibiotics or G-CSF for the prevention of infections and improvement of survival in cancer patients undergoing chemotherapy

Cancer treatment with chemotherapy (anti-cancer drugs) or bone marrow or stem cell transplantation disrupts the immune system and lowers white blood cell counts. This increases a person's risk of infection. Both granulocyte colony stimulating factors (GSF) and antibiotics can reduce the risk of infection associated with cancer treatments. The review compared the effectiveness of antibiotics to GSFs for the prevention of infection and death. Only two studies were found that compared the two methods of prophylaxis. The studies could not be pooled but both showed a non-significant trend towards a reduction of infection or fever in patients receiving antibiotics. More research is needed to determine the best prophylaxis against infection in cancer patients. 


\section{B A C K G R O U N D}

\section{Description of the condition}

Febrile neutropenia (FN) and other infectious complications are some of the most serious treatment-related toxicities of chemotherapy for cancer. The risk of febrile neutropenia and subsequent infection is directly related to the duration and severity of neutropenia (Bodey 1966; Bodey 1986). Infectious complications constitute major dose-limiting side effects in patients undergoing myelosuppressive therapy. Special risk circumstances such as patient age greater than 65 years or poor performance status impact on the associated morbidity and mortality (Kuderer 2006; Pizzo 1999). The mortality rate associated with febrile neutropenia in cancer patients is between $2 \%$ to $21 \%$ (Smith 2006).

FN can be prevented by a prophylactic regimen. Prophylaxis started upfront in the first chemotherapy cycle or in parallel with documented or anticipated neutropenia is called primary prophylaxis, whereas secondary prophylaxis is given to patients who had already experienced episodes of FN in an earlier chemotherapy cycle. Effective prophylaxis using either colony stimulating factors or antibiotics (or both) would decrease clinically relevant negative outcomes such as all cause mortality, infection-related mortality, and infectious complications. Given the high costs of the consequences of FN, and also of the colony stimulating factors themselves, economic arguments are introduced into discussions on the best prophylactic strategy (Kuderer 2006; Leibovici 2006; TjanHeijnen 2003).

Another alternative, immunglobulins is not effective in preventing infections in patients with haematological malignancies (Raanani 2008).

In clinical trials addressing the prevention of FN, granulocyte or granulocyte-macrophage colony stimulating factors (G(M)-CSFs) have been reported to be effective in reducing the duration and severity of chemotherapy-induced febrile neutropenia (Johnston 2000; Jones 1996; Holmes 2002). Prophylaxis using antibiotics has also been shown to be beneficial with reduced fever, incidence of infections, and hospitalisations (Bucaneve 2005; Cullen 2005) for example. The prophylactic strategy of combining antibiotics and G-CSF succeeded in reducing the incidence of FN as well ( Timmer-Bonte 2005).

\section{Description of the intervention}

\section{Colony stimulating factors}

$\mathrm{G}(\mathrm{M})$-CSF predominantly augments the proliferation, maturation, and release of neutrophils, resulting in a dose-dependent increase in circulating neutrophils (Bronchud 1988; Morstyn 1988). G-CSF is a growth factor for the myeloid lineage that stimulates the growth of granulocytes and eosinophil colonies; GM-CSFs also stimulate the growth of macrophages (Griffin 1990). G-CSF and GM-CSF are usually well tolerated with only a moderate number of adverse events. Limited information is available regarding differences in the incidence of adverse events between the two types of colony stimulating factors (Smith 2006). Little information is also available about the comparative efficacy of these two agents ( Smith 2006). The prophylactic efficacy of colony stimulating factors is independent of the infectious organism and they are believed to function via the shortening of the neutropenic episode. The current ASCO guidelines (Smith 2006) justify the administration of CSFs in clinical settings where the expected risk of suffering $\mathrm{FN}$ is approximately $20 \%$. In addition to the myelotoxicity of the planned chemotherapy regimen, patient-specific risk factors are to be taken into account. Secondary prophylaxis with CSFs is recommended for patients who have developed a neutropenic complication in a previous chemotherapy cycle and in whom a reduced dose might compromise disease-free or overall survival, or treatment outcome. Other guidelines such as the NCCN and the EORTC have similar recommendations (Aapro 2006; Lyman 2005).

Thus far, randomised controlled trials (Crawford 1991; TrilletLenoir 1993) and subsequent meta-analyses have shown that primary prophylaxis with CSF is effective, in both patients with solid and haematological malignancies, in reducing FN (Bohlius 2008; Hackshaw 2004; Lyman 2002; Sung 2004; Sung 2007; Wittman 2006). Furthermore, G(M)-CSFs may decrease hospitalisation and the use of intravenous therapeutic antibiotics (Crawford 1991; Trillet-Lenoir 1993). In a meta-analysis on the use of G(M)-CSFs in cancer patients hospitalised with established $\mathrm{FN}$ a possible benefit of adding G(M)-CSFs to antibiotic treatment on infection-related mortality and length of hospitalisation was observed (Clark 2005). Recently a meta-analysis by Kuderer 2006 showed that under certain standard dose chemotherapy regimens early and infection-related mortality were also reduced with primary G-CSF prophylaxis. However, none of the meta-analyses with less restrictive inclusion criteria were able to demonstrate that prophylactic administration of $\mathrm{G}(\mathrm{M})$-CSF improved overall survival when compared to placebo or no treatment. None of these analyses addressed the question of $\mathrm{G}(\mathrm{M})$-CSF versus antibiotics, which is a question closer to clinical reality. One analysis did a subgroup analysis of those studies in which the published report mandated antibiotic prophylaxis compared to those that did not and found no difference between the groups (Sung 2007). This may be due to the high number of trials where no information about antibiotic prophylaxis use is available. In addition, this meta-analysis included studies that analysed cycles of chemotherapy as opposed to patients. The distortive effect of such an analysis is difficult to estimate.

Of the many meta-analyses looking at $\mathrm{G}(\mathrm{M})$-CSF versus placebo or no treatment only one meta-analysis, restricted to patients with lymphoma, was published in The Cochrane Library (Bohlius 2008). This analysis found a reduction in the rate of infections (odds ratio (OR) 0.74 ; $95 \%$ CI 0.64 to 0.85 ) but no effect on infectionrelated mortality (OR 1.37 favouring control; 95\% CI 0.66 to

Prophylactic antibiotics or G-CSF for the prevention of infections and improvement of survival in cancer patients undergoing 
2.82). A number of other meta-analyses have been undertaken by authors funded by pharmaceutical companies that produce $G(M)$ CSFs; this was information not always disclosed in the text of the meta-analysis but retrieved from other publications by the authors (Hackshaw 2004; Kuderer 2007; Wittman 2006). These metaanalyses tended to show a stronger effect of G(M)-CSF in preventing infections and on infection-related mortality than Bohlius 2008, or reported the results as ORs and not as relative risks (RR). As an example of the former, Bohlius 2008 reported a RR of 1.37 (95\% CI 0.66 to 2.82) for the outcome infection-related mortality, from eight trials involving lymphoma patients, as compared with a RR of 0.58 (95\% CI 0.28 to 1.23) reported by Kuderer 2007 from five trials (in the subgroup of patients with lymphoma). For an example of the latter, for FN in the paediatric population of Wittman 2006 the OR was 0.59 (recalculated as RR 0.82), which compares to the RR of 0.82 reported by Sung 2007 for the paediatric patient subgroup.

\section{Antibiotics}

In contrast to the prophylactic use of $\mathrm{G}(\mathrm{M})$-CSFs, the prophylactic use of antibiotics in patients with cancer and neutropenia is more controversial. Several important guidelines are opposed to it (Lyman 2005; Smith 2006). Prophylaxis using antibiotics targets potential pathogens only and, in contrast to colony-stimulating factors, does not deal with the dose-limiting effect of haematological toxicity which is particularly relevant for dose-intensification schemes. A major concern of routine prophylactic use of antibiotics in patients with cancer and neutropenia is that it increases bacterial resistance to these agents, This may, in turn, compromise the success of treating serious infections in current as well as future patients by the spread of (multi)resistance. In addition, hypersensitivity reactions, gastrointestinal toxicities, and the promotion of fungal overgrowth after antibiotics put the patient at risk of potentially serious adverse events. Thus these aspects may limit their efficacy in reducing infection-related morbidity or mortality (Carratala 1995; Gafter-Gvili 2007; Somolinos 1992).

During the last decade, prophylaxis with antibiotics was studied in a number of randomised clinical trials. The evidence provided was not regarded as entirely convincing because none of the studies were sufficiently large to provide conclusive evidence on the real efficacy of prophylaxis (Bucaneve 2005; Cullen 2005; Karp 1987; Lew 1995). Subsequent meta-analyses suggested that prophylaxis using antibiotics reduces the incidence of gram-negative bacterial infection, total infection, fever episodes, and hospitalisation (Cruciani 2003; Engels 1998). Moreover, a recently published meta-analysis of data on antibiotic prophylaxis (or more specifically fluoroquinolones) compared to placebo or no intervention demonstrated that not only infections were reduced but all cause mortality and infection-related mortality were too (GafterGvili 2005; Leibovici 2006). One important question which is still unanswered is whether prophylaxis should be considered for all patients with cancer and neutropenia. In another meta-analysis on antibiotic prophylaxis the majority of patients were suffering from haematological malignancies and received high-dose chemotherapy and bone marrow transplantation, with only a few studies focusing on solid tumours (Cullen 2005; Gafter-Gvili 2005). Another factor possibly compromising the results of the main metaanalysis is that studies were included that randomised chemotherapy cycles and not patients, or reported cycle-based outcomes as opposed to a true incidence (where the number of patients and not cycles are analysed). Again, no information on G(M)-CSFs compared to antibiotics was available from these analyses.

\section{Why it is important to do this review}

The best prophylactic treatment of FN in cancer patients receiving myeloablative chemotherapy remains controversial and, in general, international guidelines concentrate on either antibiotics or G(M)-CSF. The evidence outlined above suggests that prophylaxis with an antibiotic might be as effective as with $\mathrm{G}(\mathrm{M})-\mathrm{CSF}$ for reducing both infections and mortality. A prospective randomised trial comparing antibiotics versus $G(M)-C S F$ in stage IV breast cancer patients treated with intermediate-dose chemotherapy showed no difference between both groups, while the cost of $\mathrm{G}(\mathrm{M})$-CSF was almost seven times higher than that of the antibiotics (Schroder 1999). To our knowledge the present Cochrane Review is the first systematic review that compares G(M)-CSFs to antibiotics, even though clinicians are currently faced with the choice of using G(M)-CSFs, antibiotics, or both.

Often the mortality rates in clinical trials of prophylactic regimes for FN are too low to allow an accurate assessment of the effect of prophylaxis on important clinical endpoints such as mortality or survival (Elting 2002). In this situation, meta-analyses that analyse much higher numbers of similarly treated patients are a suitable tool to evaluate the overall effect of regimens that showed statistically insignificant results in (underpowered) clinical trials (Paul 2005). During the systematic assessment of available evidence it is very important to account for both clinical and methodological differences in the individual trials, such as the definition of important endpoints and the multitude of different prophylaxis schedules. There may also be considerable heterogeneity introduced by different inclusion and exclusion criteria, or regional differences in pathogen epidemiology or resistance patterns.

\section{O B J E C T IVES}

To identify, critically evaluate, describe, statistically analyse, and summarise the evidence regarding the effectiveness of prophylactic antibiotic treatment compared to prophylactic use of colony stimulating factors in preventing febrile neutropenia (FN), severe infections, infection-related mortality, and overall mortality in cancer patients undergoing myelosuppressive chemotherapy. This includes bone marrow transplantation and stem cell transplantation.

Prophylactic antibiotics or G-CSF for the prevention of infections and improvement of survival in cancer patients undergoing 


\section{METHODS}

\section{Criteria for considering studies for this review}

\section{Types of studies}

Only randomised controlled trials comparing G(M)-CSF prophylaxis with antibiotic prophylaxis in cancer patients receiving myeloablative chemotherapy were included. Non-randomised and quasi-randomised studies, for example alternate treatment allocation or allocation by date of birth, were excluded as these study designs are regarded to be more prone to bias (Higgins 2006). In addition, trials looking at peri-operative infection prophylaxis, stem cell mobilisation, and priming of malignant cells with $G(M)$ CSFs were excluded.

\section{Types of participants}

We planned to include paediatric and adult, male and female patients with a confirmed diagnosis of any type of cancer who were undergoing myelosuppressive chemotherapy, bone marrow transplantation, or stem cell transplantation. Both solid and haematological malignancies were eligible.

\section{Types of interventions}

We reviewed trials comparing G(M)-CSF and antibiotics in the primary prophylaxis of infection-related complications. Trials that examined pegylated G(M)-CSF (pegfilgrastim) were eligible provided pegfilgrastim was given once, 24 hours after the completion of chemotherapy. Trials looking at secondary prophylaxis, defined as prophylaxis in a patient who suffered from $\mathrm{FN}$ in an earlier course of chemotherapy, were also eligible but a subgroup analysis was planned. No trials examining secondary prophylaxis were identified. Therapeutic interventions for FN are not part of this review.

We included studies in which the intended chemotherapy regimen did not differ between study arms. Therefore, we excluded studies which compared dose-intensified, dose-accelerated, or dose-dense regimens with standard chemotherapy as this resulted in different chemotherapy protocols in the arm that received antibiotic prophylaxis and the arm that received CSF prophylaxis. Trials with more than two arms were included provided at least two arms with the relevant comparison had the same chemotherapy protocol.

\section{Types of outcome measures}

\section{Primary outcomes}

- Overall survival

- Microbiologically or clinically, or both, documented infections

Any definition of clinically documented or microbiologically documented infections given by authors was accepted. If available, data on all and not only severe clinically or microbiologically documented infections were extracted. Microbiologically documented infections were required to have some kind of cultural confirmation of the infection. Infections reported without information on microbiological confirmation were considered to be clinically documented infections.

\section{Secondary outcomes}

- Severe infections

- Infectious episodes

- Frequency of febrile neutropenia (FN) (any definition of fever and neutropenia accepted)

- Frequency of fever (any definition)

- All cause mortality (including infection-related, treatment-related, or on-trial mortality)

- Quality of life (QoL)

In patient populations with curative treatment intent, overall survival is considered to be the most important clinical endpoint. Studies focusing on the efficacy of prophylaxis only will most likely have only short follow up, mainly providing information on early mortality. Determining the cause of death in severely ill patients can be associated with measurement bias. Therefore, all cause mortality, comprising infection-related as well as treatmentrelated mortality, was extracted.

In patient populations with palliative treatment intent, quality of life is regarded the most relevant clinical outcome measure and will thus be analysed as secondary endpoint. Only quality of life studies using a validated QoL instrument were eligible. No trial examining quality of life was retrieved.

\section{Search methods for identification of studies}

\section{Electronic searches}

A systematic and comprehensive search strategy based on the highly sensitive search filter for randomised controlled trials ( Dickersin 1994) was conducted (1985 to January 2008). The search covered the Cochrane Central Register of Controlled Trials (CENTRAL) and major medical databases (MEDLINE, EMBASE). Proceedings from relevant conferences (American Society of Clinical Oncology, American Society of Hematology) were searched (2000 to 2007).

The search strategy in Appendix 1 was used to search MEDLINE; for EMBASE see Appendix 2; and for CENTRAL see Appendix 3.

\section{Searching other resources}

In addition, we screened references from identified trials, relevant reviews, guidelines, and databases of ongoing clinical trials. No language restriction was applied. In order to avoid publication and reporting bias, abstract publications and unreported data were eligible for the review. Studies that seemed to meet inclusion criteria from their title and abstract were retrieved as full text for further evaluation. It was planned to identify duplicate reports in order to avoid duplication bias. No duplicate report was retrieved.

\section{Data collection and analysis}




\section{Study selection}

Trials were selected if they met the inclusion criteria as specified above. At every stage of searching and screening the overall number of studies identified, excluded, and included, with the reasons given, were documented in a QUOROM flow diagram (Moher 1999).

\section{Assessment of methodological quality}

At the level of the single trials

The quality of eligible studies was independently rigorously evaluated by two review authors. The following quality components, which are part of the CONSORT (Moher 2003) statement, were assessed.

1. Was treatment allocation concealed?

2. Were clinicians and participants blinded to the assigned treatment?

3. Were outcome assessors blinded to the assigned treatment?

4. Were number of withdrawals, drop outs, and losses to follow up in each group stated; and were the numbers less than $10 \%$ and equally distributed between arms?

5. Were the participants included in the analyses as part of the groups to which they were allocated (intentionto-treat analysis)?

Full-text versions of eligible studies were used to obtain data. Where these did not provide sufficient information, authors were contacted for further details. Furthermore, trials were classified as high quality trials (allocation concealment, intention-to-treat analysis with less than $10 \%$ loss, and a ratio of loss of less than 2:1 between arms) and low quality trials (not fulfilling at least one of the criteria for high quality) for a sensitivity analysis.

\section{Data extraction}

Data from the studies were extracted by two review authors (per study) using a standardised data extraction form that contained the following items.

1. General information: author, title, source, publication date, publication type (full text, abstract, unpublished).

2. Study characteristics: trial design, interventions, setting, trial dates, inclusion and exclusion criteria, comparability of groups, treatment allocation, blinding, subgroup analysis, statistics, power calculations, length of follow up, study quality, funding source.

3. Participant characteristics: age; diagnosis; stage of disease; prior treatments; number of participants recruited, allocated, and evaluated; participants lost to follow up; noticeable differences in risk factors for developing FN.

4. Interventions: duration; type; dose and timing of $\mathrm{G}(\mathrm{M})$ CSF, antibiotics, and other infection prophylaxis (e.g. antimycotics); concomitant treatment (setting, duration, type of chemotherapy); and supportive care (e.g. type of empirical antibiotic therapy).

5. Outcomes: i) primary: overall survival (results of a survival analysis with time included in the analysis), microbiologically or clinically, or both, documented infections;

ii) secondary: severe infections, infectious episodes, QoL, frequency of FN, frequency of fever, all cause mortality as a binary outcome (including infection-related, treatment-related, and early mortality).

Publications reporting on more than one trial would have been extracted using one data extraction form for each trial. Trials reported on in more than one publication would have been extracted on one form only. Extracted data were checked by a second review author. Data entry into statistical software was done by one author and checked for accuracy by a second author.

During the above steps (study selection, assessment of methodological quality, data extraction) potential disagreements between the review authors were resolved by consensus. If an agreement was not reached, a third review author was asked to give his or her opinion.

\section{Data analysis}

For statistical analysis, data were entered into Review Manager 5.0. Additional analyses that were not possible with RevMan were planned to be done in the statistical package SAS 9.12. Since no meta-analysis was possible, no further analyses were done.

Should future updates allow a meta analysis, data will be analysed as follows. All effect estimates will be obtained separately for each study and then pooled using the Mantel-Haenszel method. A fixed-effect model will be used to calculate an overall treatment effect in meta-analysis. For all analyses corresponding 95\% confidence intervals (CI) will be calculated. Time-to-event data (overall survival) will be calculated as hazard ratios (HR) based on the method introduced by Parmar (Parmar 1998; Tierney 2007). For binary data the relative risk (RR) will be used. Numbers needed to treat to benefit (NNTB) and numbers needed to treat to harm (NNTH) will be calculated for ease of interpretation.

The extent of heterogeneity between trials will be tested using a $\mathrm{Chi}^{2}$ statistic with the significance level set at $\mathrm{P}<0.10$. The $\mathrm{I}^{2}$ statistic will be used to quantify possible heterogeneity ( $\mathrm{I}^{2}>25 \%$ moderate heterogeneity, $\mathrm{I}^{2}>75 \%$ high heterogeneity). Expected causes of heterogeneity will be explored by sensitivity and subgroup analyses. If numbers of included studies allow, a linear regression test for publication bias will be conducted; a P value of less than 0.1 will be considered significant for this test. A funnel plot will be generated for visual inspection (Egger 1997; Lau 2006).

Sensitivity analyses (if possible) will be performed for: the overall quality of the studies (high or low), answers to the quality assessment questions mentioned above, duration of study, publication type, and whether the study was designed to measure overall survival.

Prophylactic antibiotics or G-CSF for the prevention of infections and improvement of survival in cancer patients undergoing 
Subgroup analyses will be performed for different types of underlying malignant disease, different baseline risk for febrile neutropenia or infection, study setting (in-patients or out-patients), different type of treatment (for example haematologic stem cell transplantation versus standard chemotherapy), different types of $\mathrm{G}(\mathrm{M})$-CSFs used, age, and according to whether regimens included antimycotic prophylaxis.

\section{Interpretation of data reviewed}

Conclusions will be based on the evidence reviewed and discussed thoroughly with the review authors. Results will be updated every two years.

\section{RE S U L T S}

\section{Description of studies}

See: Characteristics of included studies; Characteristics of excluded studies.

\section{Results of the search}

The literature search was designed to find all relevant articles where antibiotics or $\mathrm{G}(\mathrm{M})$-CSFs were used as prophylactic agents. Thus 10,924 abstracts were screened, 473 full texts evaluated briefly, and 44 considered for the review. Only two trials were included in the review. For a QUOROM-diagram see Figure 1. 
Figure I. QUORUM-Diagram

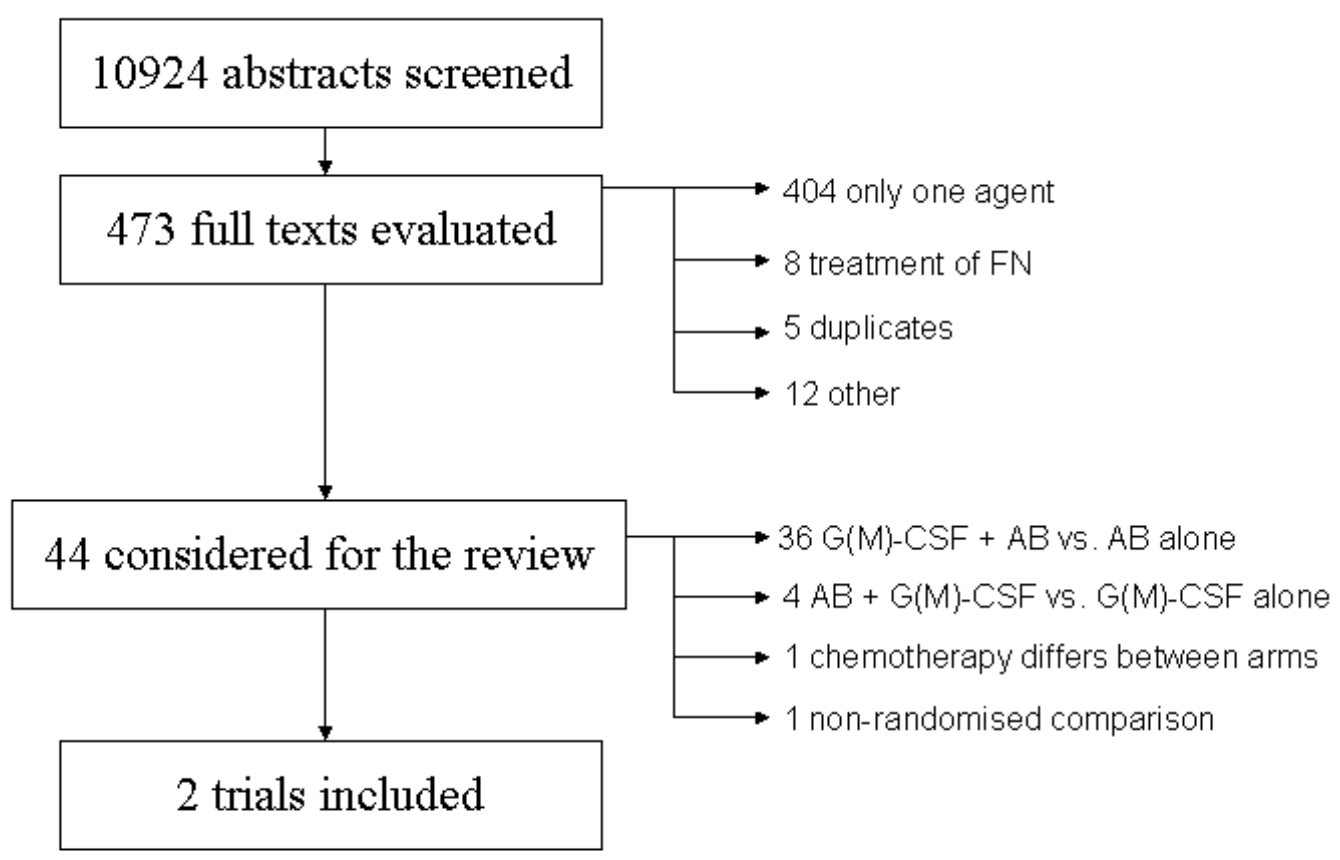




\section{Included studies}

Two studies fulfilled the entry criteria of this review. Both of the studies involved adults with solid tumours (small cell lung cancer and breast cancer) and compared prophylaxis for at least six cycles (Schroder 1999; Sculier 2001). A total of 195 patients, 40 from Schroder 1999 and 155 from Sculier 2001, were included in this review. In both studies oral antibiotics were compared to regular subcutaneous injections of G-CSF (Schroder 1999) or GM-CSF (Sculier 2001) without blinding of the study participants. Two different antibiotics were used: a combination of ciprofloxacin and amphotericin B with an anti-fungal agent (Schroder 1999), and cotrimoxazole (Sculier 2001).

The study by Sculier 2001 was a three-arm study comparing standard three-week epirubicin $90 \mathrm{mg} / \mathrm{m}^{2}$, vindesine $3 \mathrm{mg} / \mathrm{m}^{2}$, and ifosfamide $5 \mathrm{mg} / \mathrm{m}^{2}$ (EVI), given intravenously on day one, with antibiotic prophylaxis in one arm to intensive two-week EVI (same dosages) given every two weeks (intensive two-week EVI) with GM-CSF in one arm and antibiotic support in another arm. Only the two arms with the intensive two-week EVI protocol were included in the review. For the purpose of this review the standard three-week EVI arm with antibiotic prophylaxis was excluded as there was no possible comparison to a study arm that received CSF prophylaxis with the same chemotherapy protocol. Overall survival for up to 1000 days, relative and absolute dose intensity, and adverse events including the incidence of documented infections were reported.

The Schroder 1999 study randomised chemotherapy-naive patients receiving three, three-week courses of intravenous cyclophosphamide $\left(1500 \mathrm{mg} / \mathrm{m}^{2}\right)$, epirubicin $\left(80 \mathrm{mg} / \mathrm{m}^{2}\right)$, and 5 -fluouracil $\left(1500\right.$ or $1000 \mathrm{mg} / \mathrm{m}^{2}$ ) given on day one; followed by three cycles of intravenous cyclophosphamide $\left(1500 \mathrm{mg} / \mathrm{m}^{2}\right), 5-$ fluouracil $\left(600 \mathrm{mg} / \mathrm{m}^{2}\right)$ on day one and intravenous methotrexate $\left(1500 \mathrm{mg} / \mathrm{m}^{2}\right)$ on day two.

Sculier 2001 administered cotrimoxazole, $160 \mathrm{mg}$ trimethoprim, and $800 \mathrm{mg}$ sulfamethoxazole three times per day, from day three through to the end of each cycle in the antibiotic group. Schroder 1999 used two prophylactic agents in the antibiotic prophylaxis group, a combination of ciprofloxacin (250 mg twice daily) and amphotericin B (500 mg four times per day) on days three through to day 17 of each cycle. The GM-CSF dosage was $5 \mu \mathrm{g} / \mathrm{kg}$ subcutaneously from day three through to day 13 , or until neutrophils reached $1000 / \mathrm{mm}^{3}$, in the Sculier 2001 trial; and $263 \mu \mathrm{g}$ subcutaneous G-CSF (lenograstim) on days 3 through to day 12 of each cycle in the Schroder 1999 trial.

In the Schroder 1999 study episodes of hospitalisation for FN, as well as their durations, and episodes of grade four leukopenia were reported. Infection-related mortality was reported by both Schroder 1999 and Sculier 2001; overall survival, including ontrial mortality, was reported only by Sculier 2001. The only outcome reported by both studies was infection-related mortality.

\section{Excluded studies}

We excluded 36 trials that compared antibiotic and G-CSF prophylaxis to antibiotic prophylaxis alone, from either full-text information or further information obtained from the authors ( Ardizzoni 1994; Bradstock 2001; Burton 2006; Clarke 1999; Dibenedetto 1995; Faber 2006; Geissler 1997; Gonzalez-Vicent 2004; Greenberg 1996; Gulati 1992; Jones 1996; Heath 2003; Heil 1997; Lee 1998; Little 2002; McQuaker 1997; Michel 2000; Miles 1994; Nemunaitis 1995; Nolan 2007; Ojeda 1999; Ottmann 1995; Patte 2002; Pettengell 1992; Piccirillo 1999; Przepiorka 2001; Pui 1997; Schmitz 2004; Spitzer 1994; Stahel 1994; Timmer-Bonte 2005; Trigg 2000; Welte 1996; Witz 1998; Yau 1996; Zinzani 1997). Similarly, we excluded four trials that compared antibiotic prophylaxis plus $\mathrm{G}(\mathrm{M})$-CSF to $\mathrm{G}(\mathrm{M})$-CSF prophylaxis alone (Garcia 2000; Garcia-Saenz 2002; Lalami 2004; Maiche 1993). One trial was excluded because the chemotherapy (with either G-CSF prophylaxis or antibiotic prophylaxis) differed in the two arms (Tjan-Heijnen 2003). We also excluded one nonrandomised comparison (von Minckwitz 2008).

\section{Risk of bias in included studies}

\section{Allocation}

Both trials were described as randomised but the randomisation procedure was only reported by Sculier 2001 (minimisation technique). The multi-centre Sculier 2001 study reported central randomisation.

\section{Blinding}

There was no blinding in either of the studies due to the use of either an oral antibiotic or subcutaneous injections of G(M)-CSF; no information was given about whether or not the assessors were blinded.

\section{Selective reporting}

At baseline, the distribution of prognostic factors, such as age and stage of disease, were well balanced in both groups of the two studies; only limited information was given by Schroder 1999 . Withdrawals and losses to follow up were stated in the Sculier 2001 study and this study also reported intention-to-treat analysis of the various outcomes. The Schroder 1999 study used a per protocol analysis in the sense that courses of chemotherapy with incorrectly administered study drugs were excluded from the analysis.

\section{Effects of interventions}

\section{Primary outcome measures}

\section{Overall survival}

The Kaplan-Meier curves of all three arms, that is the standarddose antibiotic prophylaxis arm, the dose-dense antibiotic prophylaxis arm, and the dose-dense GM-CSF arm, were identical for the (maximum) duration of observation of 1000 days reported in the Sculier 2001 trial. This was despite dose intensification not being successful in the dose-dense antibiotic arm (the received 
dose intensity was equivalent to the dose intensity of the standard treatment protocol). The two-year survival was identical, with $6 \%$ surviving in each of the dose-dense arms.

Microbiologically or clinically documented infections

Only Sculier 2001 reported the incidence of documented infections, with infections in $17 / 78$ patients receiving GM-CSF and $11 / 77$ in patients receiving cotrimoxazole (RR 1.53; 95\% CI 0.77 to 3.04 for antibiotics, number needed to treat to benefit (NNTB) 13). This corresponded to a trend towards an increased risk of infection in patients receiving GM-CSF. A clear definition of documented infections was not given in the full-text publication of the trial.

\section{Secondary outcome measures}

Incidence of severe infections

Sculier 2001 reported the number of grade III and IV infectious episodes (classification system not mentioned) but not the incidence of infections.

Infectious episodes

Sculier 2001 described the total number of infectious episodes as $64 / 360$ cycles $(18 \%)$ in the GM-CSF group and 41/334 cycles $(12 \%)$ in the cotrimoxazole group. An OR with CIs was not calculated because the cycles were linked observations.

Quality of life (QoL)

Not reported.

Incidence of febrile neutropenia (FN)

Schroder 1999 reported hospitalisations for $\mathrm{FN}$ in 7/18 patients receiving G-CSF and in 7/22 patients receiving ciprofloxacin and amphotericin B (RR 1.22; 95\% CI 0.53 to 2.84 for antibiotics, NNTB 14). This corresponded to a trend towards an increased risk of febrile leukopenia in the group receiving G-CSF. Similar results yet slightly more in favour of ciprofloxacin and amphotericin B were reported for the analysis of courses of chemotherapy with febrile leukopenia.

Incidence or episodes of fever

Not reported.

Infection-related mortality

Infection-related mortality was the same in both groups of the Schroder 1999 trial: no patient died of infectious causes during the 18-week duration of the trial. In the Sculier 2001 trial infectionrelated mortality was similar between the two groups with $3 / 78$ infection-related deaths observed in the GM-CSF group compared to $3 / 77$ deaths in the cotrimoxazole group (OR 0.99; $95 \% \mathrm{CI}$ 0.21 to 4.74 ).

Treatment-related or early mortality

The 100-day mortality was similar in both groups in the Sculier 2001 trial with 7/78 deaths in the GM-CSF group compared to $5 / 77$ deaths in the dose-dense antibiotic group (OR 1.38; 95\% CI 0.46 to 4.17 for antibiotics, NNTB 40). This included both early deaths due to cancer and infection-related deaths.

Due to the differences in the outcomes reported (incidence of documented infections versus episodes of FN) and the lack of infectious deaths in the Schroder 1999 trial no meta-analysis of the re- sults was attempted. Note, however, that both trials reported similar but not statistically significant reductions of either infections or FN in the antibiotic arm of the study.

\section{ISCUSSION}

\section{Summary of main results}

The striking finding of this review is that there are very few studies comparing antibiotics to granulocyte (and macrophage) colony stimulating factors $(\mathrm{G}(\mathrm{M})-\mathrm{CSF})$ for infection prophylaxis in cancer patients receiving myelosuppressive chemotherapy or stem cell transplantation.

\section{Overall completeness and applicability of evidence}

Two trials were identified. Both were in patients with solid cancer and both demonstrated a trend towards a smaller number of infections in the group receiving antibiotics. However, in one of the two trials the chemotherapy dose intensity received by the antibiotic comparison group was much lower than in the GM-CSF group (Sculier 2001), which may explain the increased incidence of infections in the latter group. The lower dose intensity did not negatively affect overall survival.

\section{Agreements and disagreements with other studies or reviews}

The latest and most comprehensive meta-analysis of G(M)-CSF versus control (Sung 2007) includes over 80 trials with more than 12,000 patients for the outcome all cause mortality. Similarly the most comprehensive antibiotics versus control meta-analysis (Gafter-Gvili 2005) includes 49 trials with more than 6000 patients (for the outcome all cause mortality). The low number of trials directly comparing antibiotics to $G(M)$-CSFs is surprising considering the higher cost of G(M)-CSFs compared to standard antibiotics. However, a high number of trials comparing $G(M)$ CSFs to control received funding from pharmaceutical companies that produce $\mathrm{G}(\mathrm{M})$-CSFs. In both of the trials included in this review there was a trend towards the reduction of infections or febrile leukopenia in patients receiving antibiotic prophylaxis, and not G(M)-CSFs. Clearly more trials with larger numbers of patients are required to answer this question, in particular with regard to early infection-related mortality.

Limited data also exists from a non-randomised comparison within a randomised controlled trial by von Minckwitz 2008. In the randomised controlled trial reported by von Minckwitz 2008 the supportive care in this breast cancer study changed over time. This study was based primarily on the chemotherapy regimen of docetaxel, doxorubicin, and cyclophosphamide (TAC) and, depending on the initial response rate, patients were randomised to different numbers of cycles of TAC or to TAC compared to vinorelbine and capecitabine (NX). In patients receiving TAC, the 
incidence of febrile leukopenia was similar in patients receiving cotrimoxazole alone and daily injections of G-CSF, while patients receiving pegfilgrastim alone or pegfilgrastim and antibiotics had fewer episodes of FN. Interestingly this analysis was sponsored by a pharmaceutical company producing pegfilgrastim and only the TAC arm, and not patients receiving NX, were analysed; which makes publication bias with regard to the chemotherapy arms a possibility. In addition, missing data led to the exclusion of one third of the patients, again possibly compromising the results. While a recent meta-analysis showed that pegfilgrastim is superior to filgrastim (Pinto 2007), no randomised information is available for pegfilgrastim versus antibiotics.

Looking at this limited evidence, the recent recommendations of the ASCO and EORTC guidelines (Aapro 2006; Smith 2006) where antibiotic prophylaxis (not even with or without $G(M)$ CSF prophylaxis) is not mentioned are surprising. An argument against antibiotic prophylaxis is the occurrence of resistant strains of bacteria. However, this argument is only valid if the $\mathrm{G}(\mathrm{M})$-CSFs are not (much) worse than antibiotics in the first place - a point yet to be proven. The summary estimates of the reduction of infections (or fever, which is less prone to masking of bacterial infection through the prophylaxis used) is higher in the systematic review of antibiotics versus control than the systematic review for $\mathrm{G}(\mathrm{M})$ $\mathrm{CSF}$ versus control. Such an indirect comparison requires a careful analysis of the supportive care used, the patient populations, and study designs of the included trials. This work is underway and will be published outside The Cochrane Library.

\section{AUTHORS'CONCLUSIONS}

\section{Implications for practice}

Both antibiotics and granulocyte (and macrophage) colony stimulating factors are successful in reducing infections in cancer patients receiving myeloablative chemotherapy; see other meta-analyses (for example Gafter-Gvili 2005; Sung 2007). However, as examined here there is insufficient direct evidence from randomised controlled trials to recommend one over the other.

\section{Implications for research}

Large, high quality trials comparing antibiotic prophylaxis to infection prophylaxis using $\mathrm{G}(\mathrm{M})$-CSFs are necessary in a wide range of cancer patients.

\section{ACKNOWLEDGEMENTS}

The authors wish to thank Olaf Weingart and Nicole Skoetz of the Cochrane Haematological Malignancies Group (CHMG) Editorial Base as well as the Content Editor and the Statistic Editor for commenting on this review. We also thank the Copy-Editor Janet Wale.

\section{RE F E R E N C ES}

\section{References to studies included in this review}

Schroder 1999 \{published data only\}

Schroder CP, de Vries EG, Mulder NH, Willemse PH, Sleijfer DT, Hospers GA, et al.Prevention of febrile leucopenia after chemotherapy in high-risk breast cancer patients: no significant difference between granulocyte-colony stimulating growth factor or ciprofloxacin plus amphotericin B. Journal of Antimicrobial Chemotherapy 1999; 43:741-3.

Sculier 2001 \{published data only\}

Sculier JP, Paesmans M, Lecomte J, Van Cutsem O, Lafitte JJ, Berghmans $\mathrm{T}$, et al.A three-arm phase III randomised trial assessing, in patients with extensive-disease small-cell lung cancer, accelerated chemotherapy with support of haematological growth factor or oral antibiotics. British Journal of Cancer 2001;85(10):1444-51.

\section{References to studies excluded from this review}

\section{Ardizzoni 1994 \{published data only\}}

Ardizzoni A, Venturini M, Sertoli MR, Giannessi PG, Brema F, Danova $\mathrm{M}$, et al.Granulocyte-macrophage colony-stimulating factor (GM-CSF) allows acceleration and dose intensity increase of CEF chemotherapy: a randomised study in patients with advanced breast cancer. British Journal of Cancer 1994;69(2):385-91.

Bradstock 2001 \{published data only\}

Bradstock K, Matthews J, Young G, Lowenthal R, Baxter H, Arthur $\mathrm{C}$, et al.Effects of glycosylated recombinant human granulocyte colony-stimulating factor after high-dose cytarabine-based induction chemotherapy for adult acute myeloid leukaemia. Lenkemia 2001; 15(9):1331-8.

Burton 2006 \{published data only\} Burton C, Linch D, Hoskin P, Milligan D, Dyer MJ, Hancock B, et al.A phase III trial comparing $\mathrm{CHOP}$ to $\mathrm{PMitCEBO}$ with or without G-CSF in patients aged 60 plus with aggressive non-Hodgkin's lymphoma. British Journal of Cancer 2006;94(6):806-13.

Clarke 1999 \{published data only\}

Clarke V, Dunstan FD, Webb DK. Granulocyte colony-stimulating factor ameliorates toxicity of intensification chemotherapy for acute lymphoblastic leukemia. Medical \& Pediatric Oncology 1999;32(5): 331-5.

Dibenedetto 1995 \{published data only\} Dibenedetto SP, Ragusa R, Ippolito AM, Lo NL, Di Cataldo A, D'Amico $S$, et al.Assessment of the value of treatment with granulo- 
cyte colony-stimulating factor in children with acute lymphoblastic leukemia: a randomized clinical trial. European Journal of Haematology 1995;55(2):93-6.

Faber 2006 \{published data only\}

Faber E, Pytlik R, Slaby J, Zapletalova J, Kozak T, Raida L, et al.Individually determined dosing of filgrastim after autologous peripheral stem cell transplantation in patients with malignant lymphoma--results of a prospective multicentre controlled trial. European Journal of Haematology 2006;77(6):493-500.

Garcia 2000 \{published data only\}

Garcia G. Immediate vs. delayed imipenem treatment in cancer patients with profound neutropenia induced by high-dose chemotherapy: Results of a randomized study. Revista Espanola de Quimioterapia 2000; Vol. 15:257-63.

Garcia-Saenz 2002 \{published data only\}

Garcia-Saenz JA, Martin M, Casado A, Perez-Segura P, Manrique I, Flores L, et al.Immediate vs. delayed imipenem treatment in cancer patients with profound neutropenia induced by high-dose chemotherapy: results of a randomized study. Revista Espanola de Quimioterapia 2002;15(3):257-63.

Geissler 1997 \{published data only\}

Geissler K, Koller E, Hubmann E, Niederwieser D, Hinterberger W, Geissler D, et al.Granulocyte colony-stimulating factor as an adjunct to induction chemotherapy for adult acute lymphoblastic leukemia-a randomized phase-III study. Blood 1997;90(2):590-6.

Gonzalez-Vicent 2004 \{published data only\}

Gonzalez-Vicent M, Madero L, Sevilla J, Ramirez M, Diaz MA. A prospective randomized study of clinical and economic consequences of using G-CSF following autologous peripheral blood progenitor cell (PBPC) transplantation in children. Bone Marrow Transplantation 2004;34(12):1077-81.

Greenberg 1996 \{published data only\}

Greenberg P, Advani R, Keating A, Gulati SC, Nimer S, Champlin $\mathrm{R}$, et al.GM-CSF accelerates neutrophil recovery after autologous hematopoietic stem cell transplantation. Bone Marrow Transplantation 1996;18(6): 1057-64.

Gulati 1992 \{published data only\}

Gulati SC, Bennett CL. Granulocyte-macrophage colony-stimulating factor (GM-CSF) as adjunct therapy in relapsed Hodgkin disease. Annals of Internal Medicine 1992;116(3):177-82.

Heath 2003 \{published data only\} Heath JA, Steinherz PG, Altman A, Sather H, Jhanwar S, Halpern S, et al.Human granulocyte colony-stimulating factor in children with high-risk acute lymphoblastic leukemia: a Children's Cancer Group Study. Journal of Clinical Oncology 2003;21(8):1612-7.

Heil 1997 \{published data only\}

Heil G, Hoelzer D, Sanz MA, Lechner K, Liu Yin JA, Papa G, et al.A randomized, double-blind, placebo-controlled, phase III study of filgrastim in remission induction and consolidation therapy for adults with de novo acute myeloid leukemia. The International Acute Myeloid Leukemia Study Group. Blood 1997;90(12):4710-8.

Jones 1996 \{published data only\}

Jones SE, Schottstaedt MW, Duncan LA, Kirby RL, Good RH, Mennel RG, et al.Randomized double-blind prospective trial to evaluate the effects of sargramostim versus placebo in a moderate-dose fluorouracil, doxorubicin, and cyclophosphamide adjuvant chemotherapy program for stage II and III breast cancer. Journal of Clinical Oncology 1996;14:2976-83.

Lalami 2004 \{published data only\}

Lalami Y, Paesmans M, Aoun M, Munoz-Bermeo R, Reuss K, Cherif $\mathrm{S}$, et al.A prospective randomised evaluation of G-CSF or G-CSF plus oral antibiotics in chemotherapy-treated patients at high risk of developing febrile neutropenia. Supportive Care in Cancer 2004;12 (10):725-30.

Lee 1998 \{published data only\}

Lee SM, Radford JA, Dobson L, Huq T, Ryder WD, Pettengell $\mathrm{R}$, et al.Recombinant human granulocyte colony-stimulating factor (filgrastim) following high-dose chemotherapy and peripheral blood progenitor cell rescue in high-grade non-Hodgkin's lymphoma: clinical benefits at no extra cost. British Journal of Cancer 1998;77(8): 1294-9.

\section{Little 2002 \{published data only\}} Little MA, Morland B, Chisholm J, Hole A, Shankar A, Devine T, et al.A randomised study of prophylactic G-CSF following MRC UKALL XI intensification regimen in childhood ALL and T-NHL. Medical \& Pediatric Oncology 2002;38(2):98-103.

Maiche 1993 \{published data only\} Maiche AG, Muhonen T. Granulocyte colony-stimulating factor (GCSF) with or without a quinolone in the prevention of infection in cancer patients. European Journal of Cancer 1993;29A(10):1403-5.

McQuaker 1997 \{published data only\}

McQuaker IG, Hunter AE, Pacey S, Haynes AP, Iqbal A, Russell $\mathrm{NH}$. Low-dose filgrastim significantly enhances neutrophil recovery following autologous peripheral-blood stem-cell transplantation in patients with lymphoproliferative disorders: evidence for clinical and economic benefit (Structured abstract). Journal of Clinical Oncology 1997;15(2):451-7.

Michel 2000 \{published data only\}

Michel G, Landman-Parker J, Auclerc MF, Mathey C, Leblanc T, Legall E, et al.Use of recombinant human granulocyte colony-stimulating factor to increase chemotherapy dose-intensity: a randomized trial in very high-risk childhood acute lymphoblastic leukemia. Journal of Clinical Oncology 2000;18(7):1517-24.

Miles 1994 \{published data only\} Miles DW, Fogarty O, Ash CM, Rudd RM, Trask CW, Spiro SG, et al.Received dose-intensity: a randomized trial of weekly chemotherapy with and without granulocyte colony-stimulating factor in smallcell lung cancer. Journal of Clinical Oncology 1994;12(1):77-82.

Nemunaitis 1995 \{published data only\}

Nemunaitis J, Rosenfeld CS, Ash R, Freedman MH, Deeg HJ, Appelbaum F, et al.Phase III randomized, double-blind placebo-controlled trial of rhGM-CSF following allogeneic bone marrow transplantation. Bone Marrow Transplantation 1995;15(6):949-954.

Nolan 2007 \{published data only\}

Nolan L, Lorigan P, Chilton S, Newman J, Else R, Smith P, et al.Lowdose lenograstim is as effective as standard dose in shortening neutrophil engraftment time following myeloablative chemotherapy and peripheral blood progenitor cell rescue. British Journal of Haematology 2007; 137(5):436-42.

Prophylactic antibiotics or G-CSF for the prevention of infections and improvement of survival in cancer patients undergoing 
Ojeda 1999 \{published data only\}

Ojeda E, Garcia-Bustos J, Aguado M, Arrieta R, Quevedo E, Yuste $\mathrm{VJ}$, et al.A prospective randomized trial of granulocyte colony-stimulating factor therapy after autologous blood stem cell transplantation in adults. Bone Marrow Transplantation 1999;24(6):601-7.

Ottmann 1995 \{published data only\}

Ottmann OG, Hoelzer D, Gracien E, Ganser A, Kelly K, Reutzel $\mathrm{R}$, et al.Concomitant granulocyte colony-stimulating factor and induction chemoradiotherapy in adult acute lymphoblastic leukemia: a randomized phase III trial. Blood 1995;86(2):444-50.

Patte 2002 \{published data only\}

Patte C, Laplanche A, Bertozzi AI, Baruchel A, Frappaz D, Schmitt C, et al.Granulocyte colony-stimulating factor in induction treatment of children with non-Hodgkin's lymphoma: a randomized study of the French Society of Pediatric Oncology. Journal of Clinical Oncology 2002;20(2):441-8.

Pettengell 1992 \{published data only\} Pettengell R, Gurney H, Radford JA, Deakin DP, James R, Wilkinson $\mathrm{PM}$, et al.Granulocyte colony-stimulating factor to prevent doselimiting neutropenia in non-Hodgkin's lymphoma: a randomized controlled trial. Blood 1992;80(6):1430-6.

Piccirillo 1999 \{published data only\}

Piccirillo N, Sica S, Laurenti L, Chiusolo P, La Barbera EO, Sora F, et al.Optimal timing of G-CSF administration after CD34+ immunoselected peripheral blood progenitor cell transplantation. Bone Marrow Transplantation 1999;23(12):1245-50.

Przepiorka 2001 \{published data only\}

Przepiorka D, Smith TL, Folloder J, Anderlini P, Chan KW, Korbling $\mathrm{M}$, et al.Controlled trial of filgrastim for acceleration of neutrophil recovery after allogeneic blood stem cell transplantation from human leukocyte antigen-matched related donors. Blood 2001;97 (11):3405-10.

Pui 1997 \{published data only\}

Pui CH, Boyett JM, Hughes WT, Rivera GK, Hancock ML, Sandlund JT, et al.Human granulocyte colony-stimulating factor after induction chemotherapy in children with acute lymphoblastic leukemia. New England Journal of Medicine 1997;336(25):1781-7.

Schmitz 2004 \{published data only\}

Schmitz N, Ljungman P, Cordonnier C, Kempf C, Linkesch W, Alegre $\mathrm{A}$, et al.Lenograstim after autologous peripheral blood progenitor cell transplantation: results of a double-blind, randomized trial. Bone Marrow Transplantation 2004;34(11):955-62.

Spitzer 1994 \{published data only\}

Spitzer G, Adkins DR, Spencer V, Dunphy FR, Petruska PJ, Velasquez WS, et al.Randomized study of growth factors post-peripheral-blood stem-cell transplant: neutrophil recovery is improved with modest clinical benefit. Journal of Clinical Oncology 1994;12(4): 661-70.

Stahel 1994 \{published data only\}

Stahel RA, Jost LM, Cerny T, Pichert G, Honegger H, Tobler A, et al.Randomized study of recombinant human granulocyte colonystimulating factor after high-dose chemotherapy and autologous bone marrow transplantation for high-risk lymphoid malignancies. Journal of Clinical Oncology 1994;12(9):1931-8.
Timmer-Bonte 2005 \{published data only\}

Timmer-Bonte JN, de Boo TM, Smit HJ, Biesma B, Wilschut FA, Cheragwandi SA, et al.Prevention of chemotherapy-induced febrile neutropenia by prophylactic antibiotics plus or minus granulocyte colony-stimulating factor in small-cell lung cancer: a Dutch Randomized Phase III Study. Journal of Clinical Oncology 2005;23(31): 7974-84.

Tjan-Heijnen 2003 \{published data only\}

Tjan-Heijnen VC, Caleo S, Postmus PE, Ardizzoni A, Burghouts JT, Buccholz E, et al.Economic evaluation of antibiotic prophylaxis in small-cell lung cancer patients receiving chemotherapy: an EORTC double-blind placebo-controlled phase III study (08923). Annals of Oncology 2003;14(2):248-57.

Trigg 2000 \{published data only\}

Trigg ME, Peters C, Zimmerman MB. Administration of recombinant human granulocyte-macrophage colony-stimulating factor to children undergoing allogeneic marrow transplantation: a prospective, randomized, double-masked, placebo-controlled trial. Pediatric Transplantation 2000;4(2):123-31.

Welte 1996 \{published data only\}

Welte K, Reiter A, Mempel K, Pfetsch M, Schwab G, Schrappe $\mathrm{M}$, et al.A randomized phase-III study of the efficacy of granulocyte colony-stimulating factor in children with high-risk acute lymphoblastic leukemia. Berlin-Frankfurt-Munster Study Group. Blood 1996;87(8):3143-50.

Witz 1998 \{published data only\}

Witz F, Sadoun A, Perrin MC, Berthou C, Briere J, Cahn JY, et al.A placebo-controlled study of recombinant human granulocytemacrophage colony-stimulating factor administered during and after induction treatment for de novo acute myelogenous leukemia in elderly patients. Groupe Ouest Est Leucemies Aigues Myeloblastiques (GOELAM). Blood 1998;91(8):2722-30.

Yau 1996 \{published data only\}

Yau JC, Neidhart JA, Triozzi P, Verma S, Nemunaitis J, Quick DP, et al.Randomized placebo-controlled trial of granulocyte-macrophage colony-stimulating-factor support for dose-intensive cyclophosphamide, etoposide, and cisplatin. American Journal of Hematology 1996; 51(4):289-95.

Zinzani 1997 \{published data only\}

Zinzani PL, Pavone E, Storti S, Moretti L, Fattori PP, Guardigni L, et al.Randomized trial with or without granulocyte colony-stimulating factor as adjunct to induction VNCOP-B treatment of elderly highgrade non-Hodgkin's lymphoma. Blood 1997;89(11):3974-79.

\section{Additional references}

\section{Aapro 2006}

Aapro MS, Cameron DA, Pettengell R, Bohlius J, Crawford J, Ellis $\mathrm{M}$, et al.EORTC guidelines for the use of granulocyte-colony stimulating factor to reduce the incidence of chemotherapy-induced febrile neutropenia in adult patients with lymphomas and solid tumours. European Journal of Cancer 2006;42(15):2433-53.

\section{Bodey 1966}

Bodey GP, Buckley M, Sathe YS, Freireich EJ. Quantitative relationships between circulating leukocytes and infection in patients with acute leukemia. Annals of Internal Medicine 1966;64:328-40.

Prophylactic antibiotics or G-CSF for the prevention of infections and improvement of survival in cancer patients undergoing 
Bodey 1986

Bodey GP. Infection in cancer patients. A continuing association. American Journal of Medicine 1986;81:11-26.

\section{Bohlius 2008}

Bohlius J, Herbst C, Reiser M, Schwarzer G, Engert A. Granulopoiesis-stimulating factors to prevent adverse effects in the treatment of malignant lymphoma. Cochrane Database of Systematic Reviews 2008, Issue 4. [DOI: 10.1002/14651858]

\section{Bronchud 1988}

Bronchud MH, Potter MR, Morgenstern G, Blasco MJ, Scarffe JH, Thatcher $\mathrm{N}$, et al.In vitro and in vivo analysis of the effects of recombinant human granulocyte colony-stimulating factor in patients. British Journal of Cancer 1988;58:64-9.

Bucaneve 2005

Bucaneve G, Micozzi A, Menichetti F, Martino P, Dionisi MS, Martinelli $\mathrm{G}$, et al.. Levofloxacin to prevent bacterial infection in patients with cancer and neutropenia. New England Journal of Medicine 2005;353:977-87.

\section{Carratala 1995}

Carratala J, Fernandez-Sevilla A, Tubau F, Callis M, Gudiol F. Emergence of quinolone-resistant Escherichia coli bacteremia in neutropenic patients with cancer who have received prophylactic norfloxacin. Clinical Infectious Diseases 1995;20:557-60.

Clark 2005

Clark OA, Lyman GH, Castro AA, Clark LG, Djulbegovic B. Colony-stimulating factors for chemotherapy-induced febrile neutropenia: a meta-analysis of randomized controlled trials. Journal of Clinical Oncology 2005;23:4198-214.

\section{Crawford 1991}

Crawford J, Ozer H, Stoller R, Johnson D, Lyman G, Tabbara I, et al.Reduction by granulocyte colony-stimulating factor of fever and neutropenia induced by chemotherapy in patients with small-cell lung cancer. New England Journal of Medicine 1991;325:164-70.

\section{Cruciani 2003}

Cruciani M, Malena M, Bosco O, Nardi S, Serpelloni G, Mengoli C. Reappraisal with meta-analysis of the addition of Gram-positive prophylaxis to fluoroquinolone in neutropenic patients. Journal of Clinical Oncology 2003;21:4127-37.

\section{Cullen 2005}

Cullen M, Steven N, Billingham L, Gaunt C, Hastings M, Simmonds $\mathrm{P}$, et al.Antibacterial prophylaxis after chemotherapy for solid tumors and lymphomas. New England Journal of Medicine 2005;353:98898.

\section{Dickersin 1994}

Dickersin K, Scherer R, Lefebre C. Identifying relevant studies for systematic reviews. BMJ 1994;309:1286-91.

\section{Egger 1997}

Egger M, Davey SG, Schneider M, Minder C. Bias in meta-analysis detected by a simple, graphical test. BMJ 1997;315(7109):629-34.

\section{Elting 2002}

Elting LS, Cantor SB. Outcomes and costs of febrile neutropenia: adventures in the science and art of treatment choices. Support Care Cancer 2002;10(3):189-96.

\section{Engels 1998}

Engels EA, Lau J, Barza M. Efficacy of quinolone prophylaxis in neutropenic cancer patients: a meta-analysis. Journal of Clinical Oncology 1998;16:1179-87.

\section{Gafter-Gvili 2005}

Gafter-Gvili A, Fraser A, Paul M, Leibovici L. Meta-Analysis: Antibiotic Prophylaxis Reduces Mortality in Neutropenic Patients. Annals of Internal Medicine 2005;142:979-95.

\section{Gafter-Gvili 2007}

Gafter-Gvili A, Paul M, Fraser A, Leibovici L. Effect of quinolone prophylaxis in afebrile neutropenic patients on microbial resistance: systematic review and meta-analysis. Journal of Antimicrobial Chemotherapy 2007;59(1):5-22.

\section{Griffin 1990}

Griffin JD, Cannistra SA, Sullivan R, Demetri GD, Ernst TJ, Kanakura Y. The biology of GM-CSF: regulation of production and interaction with its receptor. International Journal of Cell Cloning 1990;8 Suppl 1:35-44.

\section{Hackshaw 2004}

Hackshaw A, Sweetenham J, Knight A. Are prophylactic haematopoietic growth factors of value in the management of patients with aggressive non-Hodgkin's lymphoma?. British Journal of Cancer 2004; 90:1302-5.

\section{Higgins 2006}

Higgins JPT, Green S, editors. Cochrane Handbook for Systematic Reviews of Interventions 5.0.0 [updated February 2008]. http: //www.cochrane.org/resources/handbook/ (accessed 19 June 2008).

\section{Holmes 2002}

Holmes FA, Jones SE, O'Shaughnessy J, Vukelja S, George T, Savin $\mathrm{M}$, et al.Comparable efficacy and safety profiles of once-per-cycle pegfilgrastim and daily injection filgrastim in chemotherapy-induced neutropenia: a multicenter dose-finding study in women with breast cancer. Annals of Oncology 2002;13(6):903-9.

\section{Johnston 2000}

Johnston E, Crawford J, Blackwell S, Bjurstrom T, Lockbaum P, Roskos L, et al.Randomized, dose-escalation study of SD/01 compared with daily filgrastim in patients receiving chemotherapy. Journal of Clinical Oncology 2000;18:2522-8.

\section{Jones 1996}

Jones SE, Schottstaedt MW, Duncan LA, Kirby RL, Good RH, Mennel RG, et al.Randomized double-blind prospective trial to evaluate the effects of sargramostim versus placebo in a moderate-dose fluorouracil, doxorubicin, and cyclophosphamide adjuvant chemotherapy program for stage II and III breast cancer. Journal of Clinical Oncology 1996;14:2976-83.

\section{Karp 1987}

Karp JE, Merz WG, Hendricksen C, Laughon B, Redden T, Bamberger BJ, Bartlett JG, et al.Oral norfloxacin for prevention of gramnegative bacterial infections in patients with acute leukemia and granulocytopenia. A randomized, double-blind, placebo-controlled trial. Annals of Internal Medicine 1987;106:1-7.

\section{Kuderer 2006}

Kuderer NM, Dale DC, Crawford J, Cosler LE, Lyman GH. Mortality, morbidity, and cost associated with febrile neutropenia in adult cancer patients. Cancer 2006; 106:2258-66. 
Kuderer 2007

Kuderer NM, Dale DC, Crawford J, Lyman GH. Impact of primary prophylaxis with granulocyte colony-stimulating factor on febrile neutropenia and mortality in adult cancer patients receiving chemotherapy: a systematic review. Journal of Clinical Oncology 2007;25 (21):3158-67.

Lau 2006

Lau J, Ioannidis JP, Terrin N, Schmid CH, Olkin I. The case of the misleading funnel plot. BMJ 2006;333(7568):597-600.

\section{Leibovici 2006}

Leibovici L, Paul M, Cullen M, Bucaneve G, Gafter-Gvili A, Fraser A, et al.Antibiotic prophylaxis in neutropenic patients: new evidence, practical decisions. Cancer 2006;107(8):1743-51.

\section{Lew 1995}

Lew MA, Kehoe K, Ritz J, Antman KH, Nadler L, Kalish LA, et al.Ciprofloxacin versus trimethoprim/sulfamethoxazole for prophylaxis of bacterial infections in bone marrow transplant recipients: a randomized, controlled trial. Journal of Clinical Oncology 1995;13 (1):239-50.

Lyman 2002

Lyman GH, Kuderer NM, Djulbegovic B. Prophylactic granulocyte colony-stimulating factor in patients receiving dose-intensive cancer chemotherapy: A meta-analysis. American Journal of Medicine 2002; 112:406-11.

Lyman 2005

Lyman GH. Pegfilgrastim: a granulocyte colony-stimulating factor with sustained duration of action.. Expert Opinion on Biological Therapy 2005;5(12):1635-46.

\section{Moher 1999}

Moher D, Cook DJ, Eastwood S, Olkin I, Rennie D, Stroup DF. Improving the quality of reports of meta-analyses of randomised controlled trials: the QUORUM statement. Quality of reporting of meta-analyses. Lancet 1999;354:1896-900.

\section{Moher 2003}

Moher D, Schulz KF, Altman DG. The CONSORT statement: revised recommendations for improving the quality of reports of parallel-group randomised trials. Clinical Oral Investigation 2003;7:2-7.

\section{Morstyn 1988}

Morstyn G, Campbell L, Souza LM, Alton NK, Keech J, Green M, et al.Effect of granulocyte colony stimulating factor on neutropenia induced by cytotoxic chemotherapy. Lancet 1988;1:667-72.

\section{Parmar 1998}

Parmar MK, Torri V, Stewart L. Extracting summary statistics to perform meta-analyses of the published literature for survival endpoints. Statistics in Medicine 1998;17(24):2815-34.

\section{Paul 2005}

Paul M, Leibovici L. Systematic reviews and meta-analysis of febrile neutropenia. Mayo Clinical Proceedings 2005;80(9):1122-5.

Pinto 2007

Pinto L, Liu Z, Doan Q, Bernal M, Dubois R, Lyman G. Comparison of pegfilgrastim with filgrastim on febrile neutropenia, grade IV neutropenia and bone pain: a meta-analysis of randomized controlled trials. Current Medical Research \& Opinion 2007;23(9):2283-95.

\section{Pizzo 1999}

Pizzo PA. Fever in immunocompromised patients. New England Journal of Medicine 1999;341(12):893-900.

\section{Raanani 2008}

Raanani P, Gafter-Gvili A, Paul M, Ben-Bassat I, Leibovici L, Shpilberg O. Immunoglobulin prophylaxis in hematological malignancies and hematopoietic stem cell transplantation. Cochrane Database of Systematic Reviews 2008, Issue 4. [DOI: 10.1002/14651858.]

\section{Smith 2006}

Smith TJ, Khatcheressian J, Lyman GH, Ozer H, Armitage JO, Balducci $\mathrm{L}$, et al.2006 update of recommendations for the use of white blood cell growth factors: an evidence-based clinical practice guideline. Journal of Clinical Oncology 2006;24:3187-205.

Somolinos 1992

Somolinos N, Arranz R, Del Rey MC, Jimenez ML. Superinfections by Escherichia coli resistant to fluoroquinolones in immunocompromised patients. Journal of Antimicrobial Chemotherapy 1992;30: $730-1$.

Sung 2004

Sung L, Nathan PC, Lange B, Beyene J, Buchanan JR. Prophylactic granulocyte colony-stimulating factor and granulocyte-macrophage colony-stimulating factor decrease febrile neutropenia after chemotherapy in children with cancer: A meta-analysis of randomized controlled trials. Journal of Clinical Oncology 2004;22:3350-6.

Sung 2007

Sung L, Nathan PC, Alibhai SM, Tomlinson GA, Beyene J. Metaanalysis: effect of prophylactic hematopoietic colony-stimulating factors on mortality and outcomes of infection. Annals of Internal Medicine 2007;147(6):400-11.

Tierney 2007

Tierney JF, Stewart LA, Ghersi D, Burdett S, Sydes MR. Practical methods for incorporating summary time-to-event data into metaanalysis. Trials 2007;8:16

\section{Timmer-Bonte 2005}

Timmer-Bonte JN, de Boo TM, Smit HJ, Biesma B, Wilschut FA, Cheragwandi SA, et al.Prevention of chemotherapy-induced febrile neutropenia by prophylactic antibiotics plus or minus granulocyte colony-stimulating factor in small-cell lung cancer: a Dutch Randomized Phase III Study. Journal of Clinical Oncology 2005;23(31) 7974-84.

Trillet-Lenoir 1993

Trillet-Lenoir V, Green J, Manegold C, Von Pawel J, Gatzemeier U, Lebeau B, et al.Recombinant granulocyte colony stimulating factor reduces the infectious complications of cytotoxic chemotherapy. $\mathrm{Eu}$ ropean Journal of Cancer 1993;29A:319-24.

\section{von Minckwitz 2008}

von Minckwitz G, Kummel S, du BA, Eiermann W, Eidtmann H, Gerber B, et al.Pegfilgrastim +/- ciprofloxacin for primary prophylaxis with TAC (docetaxel/doxorubicin/cyclophosphamide) chemotherapy for breast cancer. Results from the GEPARTRIO study. Annals of Oncology 2008;19(2):292-8.

\section{Wittman 2006}

Wittman B, Horan J, Lyman GH. Prophylactic colony-stimulating factors in children receiving myelosuppressive chemotherapy: a meta- 
analysis of randomized controlled trials. Cancer Treatment Reviews

2006;32(4):289-303.

* Indicates the major publication for the study

\section{CHARACTERISTICSOF STUDIES}

Characteristics of included studies [ordered by study ID]

\section{Schroder 1999}

\begin{tabular}{|c|c|c|}
\hline Methods & \multicolumn{2}{|c|}{$\begin{array}{l}\text { Chemotherapy regimen ( } 3 \text { week cycle): cyclophosphamide } 1500 \mathrm{mg} / \mathrm{m}^{2}, \text { epirubicin } 80 \mathrm{mg} / \mathrm{m}^{2}, \mathrm{~F}-\mathrm{FU} \\
1000 \mathrm{mg} / \mathrm{m}^{2} \text { on day one of the first six cycle then cyclophosphamide } 1500 \mathrm{mg} / 2,5-\mathrm{FU} 600 \mathrm{mg} / \mathrm{m}^{2} \text { on day } \\
\text { one and iv methotrexate } 1500 \mathrm{mg} / \mathrm{m}^{2} \text { on day two for additional } 3 \text { cycles }\end{array}$} \\
\hline Participants & \multicolumn{2}{|c|}{40 patients with de novo metastatic breast cancer, age $<65$ years } \\
\hline Interventions & \multicolumn{2}{|c|}{$\begin{array}{l}\text { Antibiotic arm: oral ciprofloxacin } 2 \text { X } 250 \mathrm{mg} \text { daily + oral amphotericin B } 100 \mathrm{mg} / \mathrm{ml} 4 \text { X } 5 \mathrm{ml} \text { daily on } \\
\text { days } 3 \text { through } 17\end{array}$} \\
\hline Outcomes & \multicolumn{2}{|c|}{$\begin{array}{l}\text { episodes of hospitalisation for febrile neutropenia, duration of hospitalisation for febrile neutropenia, grade } \\
\text { four leucopenia }\end{array}$} \\
\hline Notes & \multicolumn{2}{|c|}{ No blinding (oral versus sc injections) } \\
\hline \multicolumn{3}{|l|}{ Risk of bias } \\
\hline Item & Authors' judgement & Description \\
\hline $\begin{array}{l}\text { Blinding? } \\
\text { All outcomes }\end{array}$ & No & \\
\hline
\end{tabular}

Sculier 2001

\begin{tabular}{l|l} 
Methods & $\begin{array}{l}3 \text { arm study: standard } 3 \text { week chemotherapy regimen, intensive } 2 \text { week chemotherapy regimen with } \\
\text { antibiotic or G-CSF support. Chemotherapy regimen }\left(6 \text { cycles): epirubicin } 90 \mathrm{mg} / \mathrm{m}^{2}, \text { vindesine } 5 \mathrm{mg} / \mathrm{m}^{2},\right. \\
\text { ifosfamide } 5 \mathrm{mg} / \mathrm{m}^{2}\end{array}$ \\
\hline Participants & $\begin{array}{l}\text { Untreated extensive disease small cell lung cancer, age }<75 \mathrm{y} \text {, adequate haematological, renal and hepatic } \\
\text { function, no recent myocardial infarction or congestive heart failure, performance status (Karnovski }>= \\
60)\end{array}$ \\
\hline Interventions & $\begin{array}{l}\text { Antibiotic arm: trimethoprim } 160 \mathrm{mg} / \text { sulfamethoxale } 800 \mathrm{mg} \text { orally every } 12 \text { hours from day } 3 \text { of the first } \\
\text { course of chemotherapy until the end of the courses. GM-CSF arm: } 5 \mu \mathrm{kg} \text { GM-CSF (Leucomax) from } \\
\text { day } 3 \text { to } 13 \text { of each cycle or until ANC }>1000 / \mu \mathrm{l}\end{array}$
\end{tabular}




\section{Sculier 2001 (Continued)}

\begin{tabular}{|c|c|c|}
\hline Outcomes & \multicolumn{2}{|c|}{$\begin{array}{l}\text { Absolute and relative dose intensity, response rate, overall survival, adverse events, incidence of infections } \\
\text { and severe infections }\end{array}$} \\
\hline Notes & \multicolumn{2}{|c|}{$\begin{array}{l}\text { Only the intensive chemotherapy regimen included in meta-analysis. No blinding (oral medication versus } \\
\text { sc injections) }\end{array}$} \\
\hline \multicolumn{3}{|l|}{ Risk of bias } \\
\hline Item & Authors' judgement & Description \\
\hline Allocation concealment? & Yes & \\
\hline $\begin{array}{l}\text { Blinding? } \\
\text { All outcomes }\end{array}$ & No & \\
\hline
\end{tabular}

Characteristics of excluded studies [ordered by study ID]

\begin{tabular}{|c|c|}
\hline Ardizzoni 1994 & Comparison of $\mathrm{G}(\mathrm{M})$-CSF plus antibiotics versus antibiotics alone \\
\hline Bradstock 2001 & Comparison of $\mathrm{G}(\mathrm{M})$-CSF plus antibiotics versus antibiotics alone \\
\hline Burton 2006 & Comparison of $\mathrm{G}(\mathrm{M})$-CSF plus antibiotics versus antibiotics alone \\
\hline Clarke 1999 & Comparison of $\mathrm{G}(\mathrm{M})$-CSF plus antibiotics versus antibiotics alone \\
\hline Dibenedetto 1995 & Comparison of $\mathrm{G}(\mathrm{M})$-CSF plus antibiotics versus antibiotics alone \\
\hline Faber 2006 & Comparison of $\mathrm{G}(\mathrm{M})$-CSF plus antibiotics versus antibiotics alone \\
\hline Garcia 2000 & Comparison of antibiotics plus $\mathrm{G}(\mathrm{M})$-CSF versus $\mathrm{G}(\mathrm{M})$-CSF alone \\
\hline Garcia-Saenz 2002 & Comparison of antibiotics plus $\mathrm{G}(\mathrm{M})$-CSF versus $\mathrm{G}(\mathrm{M})$-CSF alone \\
\hline Geissler 1997 & Comparison of $\mathrm{G}(\mathrm{M})$-CSF plus antibiotics versus antibiotics alone \\
\hline Gonzalez-Vicent 2004 & Comparison of $\mathrm{G}(\mathrm{M})$-CSF plus antibiotics versus antibiotics alone \\
\hline Greenberg 1996 & Comparison of $\mathrm{G}(\mathrm{M})$-CSF plus antibiotics versus antibiotics alone \\
\hline Gulati 1992 & Comparison of $\mathrm{G}(\mathrm{M})$-CSF plus antibiotics versus antibiotics alone \\
\hline Heath 2003 & Comparison of $\mathrm{G}(\mathrm{M})$-CSF plus antibiotics versus antibiotics alone \\
\hline
\end{tabular}


(Continued)

\begin{tabular}{|c|c|}
\hline Heil 1997 & Comparison of $\mathrm{G}(\mathrm{M})$-CSF plus antibiotics versus antibiotics alone \\
\hline Jones 1996 & Comparison of $\mathrm{G}(\mathrm{M})$-CSF plus antibiotics versus antibiotics alone \\
\hline Lalami 2004 & Comparison of antibiotics plus G-CSF versus G-CSF alone \\
\hline Lee 1998 & Comparison of $\mathrm{G}(\mathrm{M})$-CSF plus antibiotics versus antibiotics alone \\
\hline Little 2002 & Comparison of $\mathrm{G}(\mathrm{M})$-CSF plus antibiotics versus antibiotics alone \\
\hline Maiche 1993 & Comparison of antibiotics plus G-CSF versus G-CSF alone \\
\hline McQuaker 1997 & Comparison of $\mathrm{G}(\mathrm{M})$-CSF plus antibiotics versus antibiotics alone \\
\hline Michel 2000 & Comparison of $\mathrm{G}(\mathrm{M})$-CSF plus antibiotics versus antibiotics alone \\
\hline Miles 1994 & Comparison of $\mathrm{G}(\mathrm{M})$-CSF plus antibiotics versus antibiotics alone \\
\hline Nemunaitis 1995 & Comparison of $\mathrm{G}(\mathrm{M})$-CSF plus antibiotics versus antibiotics alone \\
\hline Nolan 2007 & Comparison of $\mathrm{G}(\mathrm{M})$-CSF plus antibiotics versus antibiotics alone \\
\hline Ojeda 1999 & Comparison of $\mathrm{G}(\mathrm{M})$-CSF plus antibiotics versus antibiotics alone \\
\hline Ottmann 1995 & Comparison of $\mathrm{G}(\mathrm{M})$-CSF plus antibiotics versus antibiotics alone \\
\hline Patte 2002 & Comparison of $\mathrm{G}(\mathrm{M})$-CSF plus antibiotics versus antibiotics alone \\
\hline Pettengell 1992 & Comparison of G(M)-CSF plus antibiotics versus antibiotics alone \\
\hline Piccirillo 1999 & Comparison of $\mathrm{G}(\mathrm{M})$-CSF plus antibiotics versus antibiotics alone \\
\hline Przepiorka 2001 & Comparison of $\mathrm{G}(\mathrm{M})$-CSF plus antibiotics versus antibiotics alone \\
\hline Pui 1997 & Comparison of $\mathrm{G}(\mathrm{M})$-CSF plus antibiotics versus antibiotics alone \\
\hline Schmitz 2004 & Comparison of $\mathrm{G}(\mathrm{M})$-CSF plus antibiotics versus antibiotics alone \\
\hline Spitzer 1994 & Comparison of $\mathrm{G}(\mathrm{M})$-CSF plus antibiotics versus antibiotics alone \\
\hline Stahel 1994 & Comparison of $\mathrm{G}(\mathrm{M})$-CSF plus antibiotics versus antibiotics alone \\
\hline Timmer-Bonte 2005 & Comparison of G(M)-CSF plus antibiotics versus antibiotics alone \\
\hline
\end{tabular}

Prophylactic antibiotics or G-CSF for the prevention of infections and improvement of survival in cancer patients undergoing 
(Continued)

Tjan-Heijnen 2003

4-arm study, two with intensive chemotherapy (G-CSF versus G-CSF + antibiotics) and two with standard dose chemotherapy (control versus antibiotics). Excluded due to the differences in the chemotherapy regimens between antibiotics and G-CSF.

Trigg $2000 \quad$ Comparison of G(M)-CSF plus antibiotics versus antibiotics alone

Welte 1996 Comparison of G(M)-CSF plus antibiotics versus antibiotics alone

Witz 1998 Comparison of G(M)-CSF plus antibiotics versus antibiotics alone

Yau 1996 Comparison of G(M)-CSF plus antibiotics versus antibiotics alone

Zinzani $1997 \quad$ Comparison of $\mathrm{G}(\mathrm{M})$-CSF plus antibiotics versus antibiotics alone 


\section{DATA ANDANALYSES}

This review has no analyses.

\section{A P P E N D I CES}

\section{Appendix I. MEDLINE search strategy}

1. $\exp$ ANTI-BACTERIAL AGENTS/

2. (antibacterial\$ or anti-bacterial\$).tw,kf,ot.

3. antibio\$.tw,kf,ot.

4. (antimicrobial\$ or anti-microbial\$).tw,kf,ot.

5. (anti-mycobacterial\$ or antimycobacterial\$).tw,kf,ot.

6. bacteriocid\$.tw,kf,ot.

7. (selective $\$$ adj3 decontaminat\$).tw,kf,ot.

8. ANTIBIOTIC PROPHYLAXIS/

9. $\exp$ QUINOLONE/

10. fluoroquinolones $\$$.tw,kf,ot.

11. ciprofloxa\#in $\$ . t w, k f$,ot.

12. ofloxa\#in $\$ . t w, k f$,ot.

13. norfloxa\#in $\$$.tw,kf,ot.

14. enoxa\#in\$.tw,kf,ot.

15. pefloxa\#in\$.tw,kf,ot.

16. exp TRIMETHOPRIM/

17. trimethoprim $\$$.tw,kf,ot.

18. sulfamethoxazol\$.tw,kf,ot.

19. trimethoprim-sulfamethoxazol\$.tw,kf,ot.

20. tmp-smz\$.tw,kf,ot.

21. exp POLYMYXINS/

22. colistin $\$ . t w, k f, o t$.

23. (nalidixic\$ adj3 acid\$).tw,kf,ot.

24. polymyxin $\$$.tw,kf,ot.

25. AMINOGLYCOSIDES/

26. GENTAMICINS/

27. gentami\#in\$.tw,kf,ot.

28. $\operatorname{exp~NEBRAMYCIN/~}$

29. tobramy\#in\$.tw,kf,ot.

30. NEOMYCIN/

31. neomy\#in\$.tw,kf,ot.

32. VANCOMYCIN/.

33. vancomy\#in\$.tw,kf,ot.

34. ROXITHROMYCIN/

35. roxithromy\#in\$.tw,kf,ot.

36. RIFAMPIN/

37. (rifampin\$ or rifampicin\$).tw,kf,ot.

38. BETA-LACTAMS/

39. beta-lactam $\$$.tw,kf,ot.

40. PENICILLINS/

41. peni\#illin\$.tw,kf,ot.

42. AMOXICILLIN/

43. amoxi\#illin\$.tw,kf,ot.

44. CEPHALOTHIN/

45. (cephalot?in \$ or cefalot?in\$).tw,kf,ot.

Prophylactic antibiotics or G-CSF for the prevention of infections and improvement of survival in cancer patients undergoing 


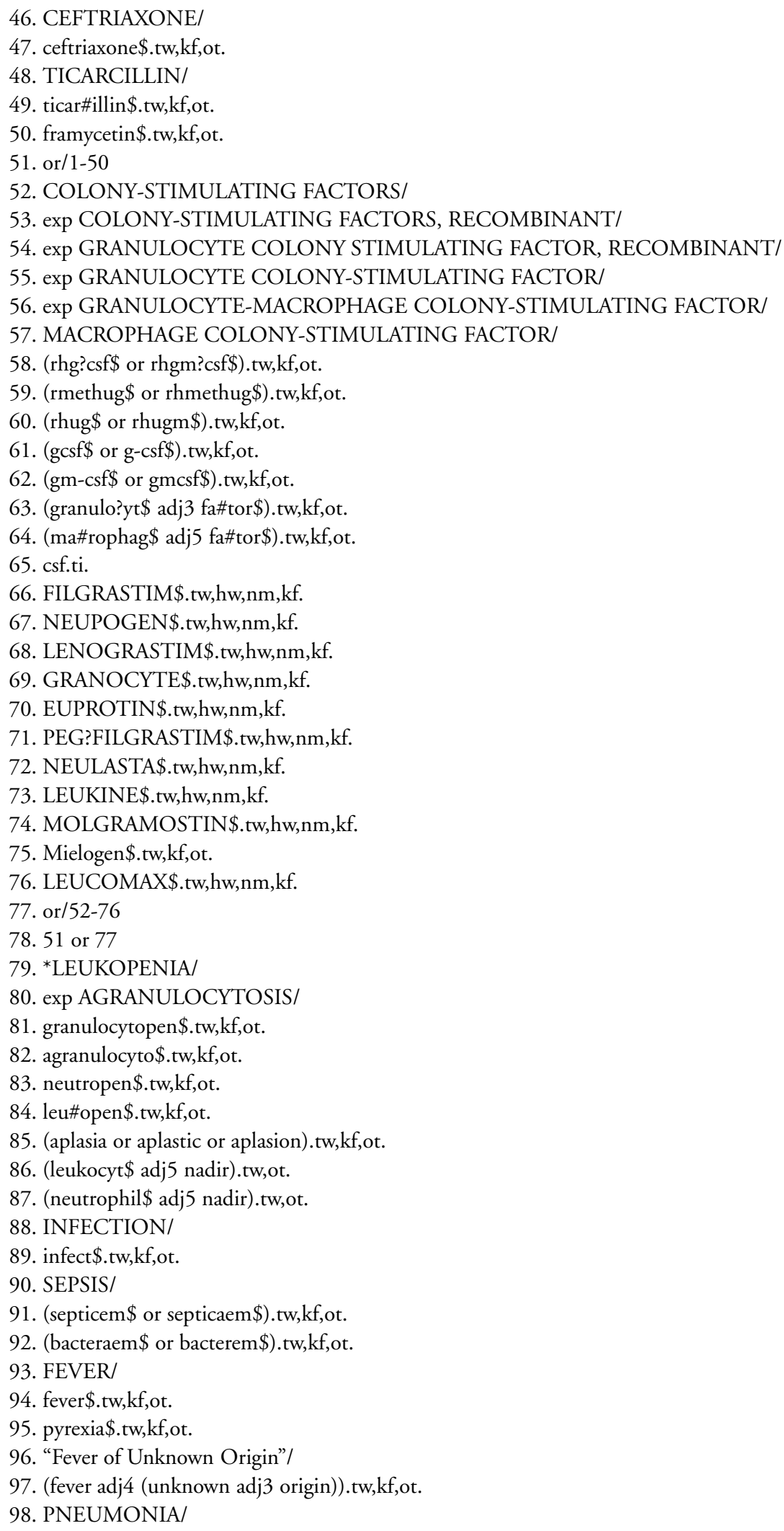

Prophylactic antibiotics or G-CSF for the prevention of infections and improvement of survival in cancer patients undergoing 
99. ((lung\$ or pulmon\$) and inflammation\$).tw,kf,ot.

100. pneumonit\$.tw,kf,ot.

101. engraftment\$.tw,kf,ot.

102. (neutrophil\$ adj3 recover\$).tw,kf,ot.

103. (haematolog $\$$ adj3 recover\$).tw,kf,ot.

104. (hematolog\$ adj3 recover\$).tw,kf,ot.

105. or/79-104

106. exp NEOPLASMS BY HISTOLOGIC TYPE/

107. exp NEOPLASMS BY SITE/

108. neoplas\$.tw,kf,ot.

109. tumo?r\$.tw,kf,ot.

110. (krebs\$ or cancer\$).tw,kf,ot.

111. malignan $\$ . t w, k f, o t$.

112. (carcino\$ or karzino\$).tw,kf,ot.

113. karzinom $\$$.tw,kf,ot.

114. sarcom\$.tw,kf,ot.

115. leuk\#?m\$.tw,kf,ot.

116. lymphom\$.tw,kf,ot.

117. melano\$.tw,kf,ot.

118. metastas\$.tw,kf,ot.

119. (mesothelio\$ or mesotelio\$).tw,kf,ot.

120. carcinomatos $\$$.tw,kf,ot.

121. (gliom\$ or glioblastom\$).tw,kf,ot.

122. osteo?sarcom $\$$.tw,kf,ot.

123. (blastom\$ or neuroblastom\$).tw,kf,ot.

124. or/106-123

125. 105 and 124

126. 78 and 125

127. randomized controlled trial.pt.

128. controlled clinical trial.pt.

129. RANDOMIZED CONTROLLED TRIALS/

130. RANDOM ALLOCATION/

131. DOUBLE BLIND METHOD/

132. SINGLE BLIND METHOD/

133. or/127-132

134. (ANIMALS not HUMANS)/

135. 133 not 134

136. clinical trial.pt.

137. exp CLINICAL TRIALS/

138. (clin\$ adj25 trial\$).ti,ab.

139. ((singl\$ or doubl\$ or trebl\$ or tripl\$) adj25 (blind\$ or mask\$)).ti,ab.

140. PLACEBOS/

141. placebo\$.ti,ab.

142. random\$.ti,ab.

143. RESEARCH DESIGN/

144. or/136-143

145. 144 not 134

146. 145 not 135

147. COMPARATIVE STUDY/

148. exp EVALUATION STUDIES/

149. FOLLOW UP STUDIES/

150. PROSPECTIVE STUDIES/

151. (control\$ or prospectiv\$ or volunteer\$).ti,ab.

Prophylactic antibiotics or G-CSF for the prevention of infections and improvement of survival in cancer patients undergoing 
152. or/143-147

153. 152 not 134

154. 153 not (135 or 146$)$

155. 135 or 146 or 154

156. 126 and 155

\section{Appendix 2. EMBASE search strategy}

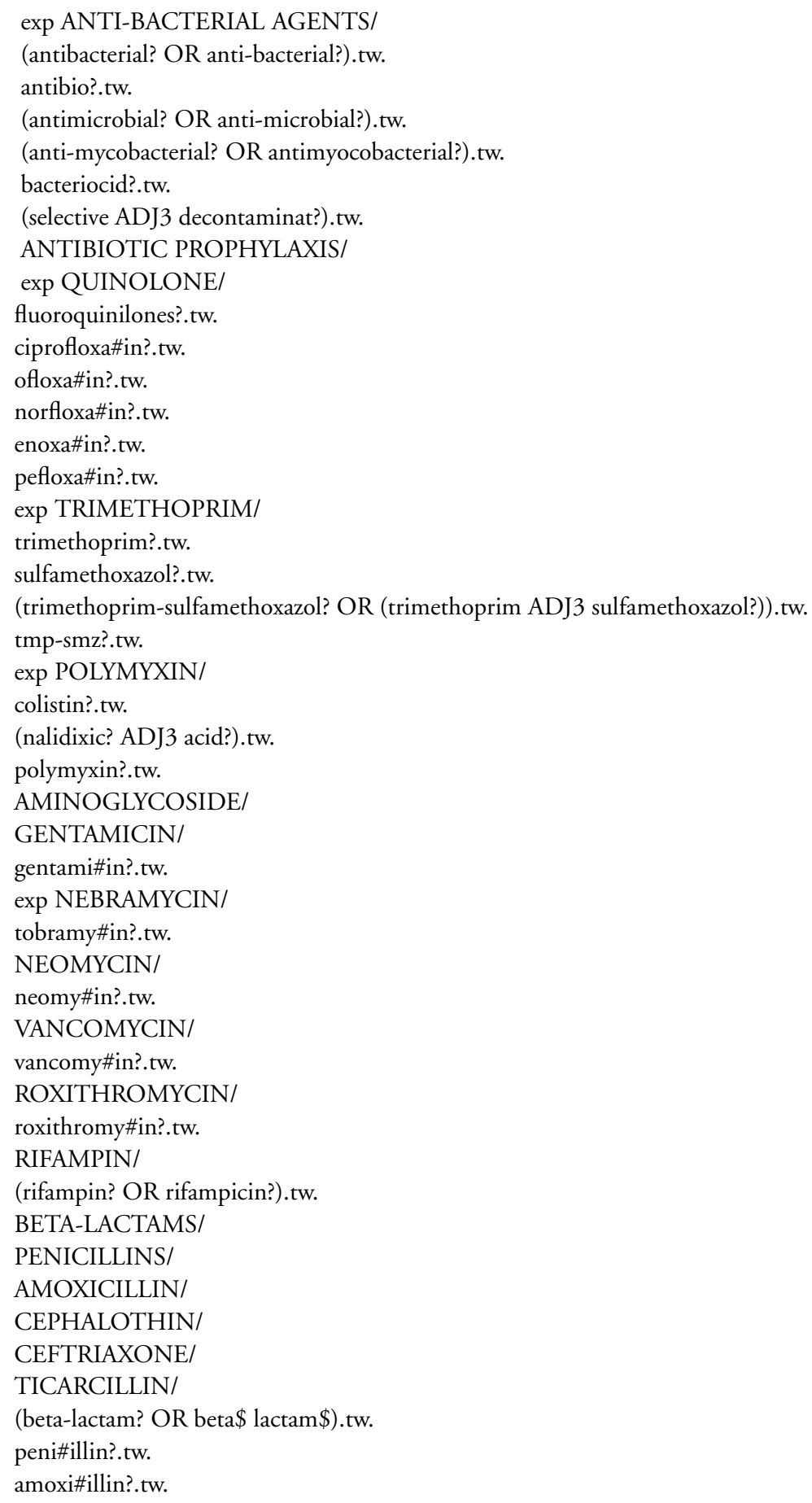

Prophylactic antibiotics or G-CSF for the prevention of infections and improvement of survival in cancer patients undergoing 


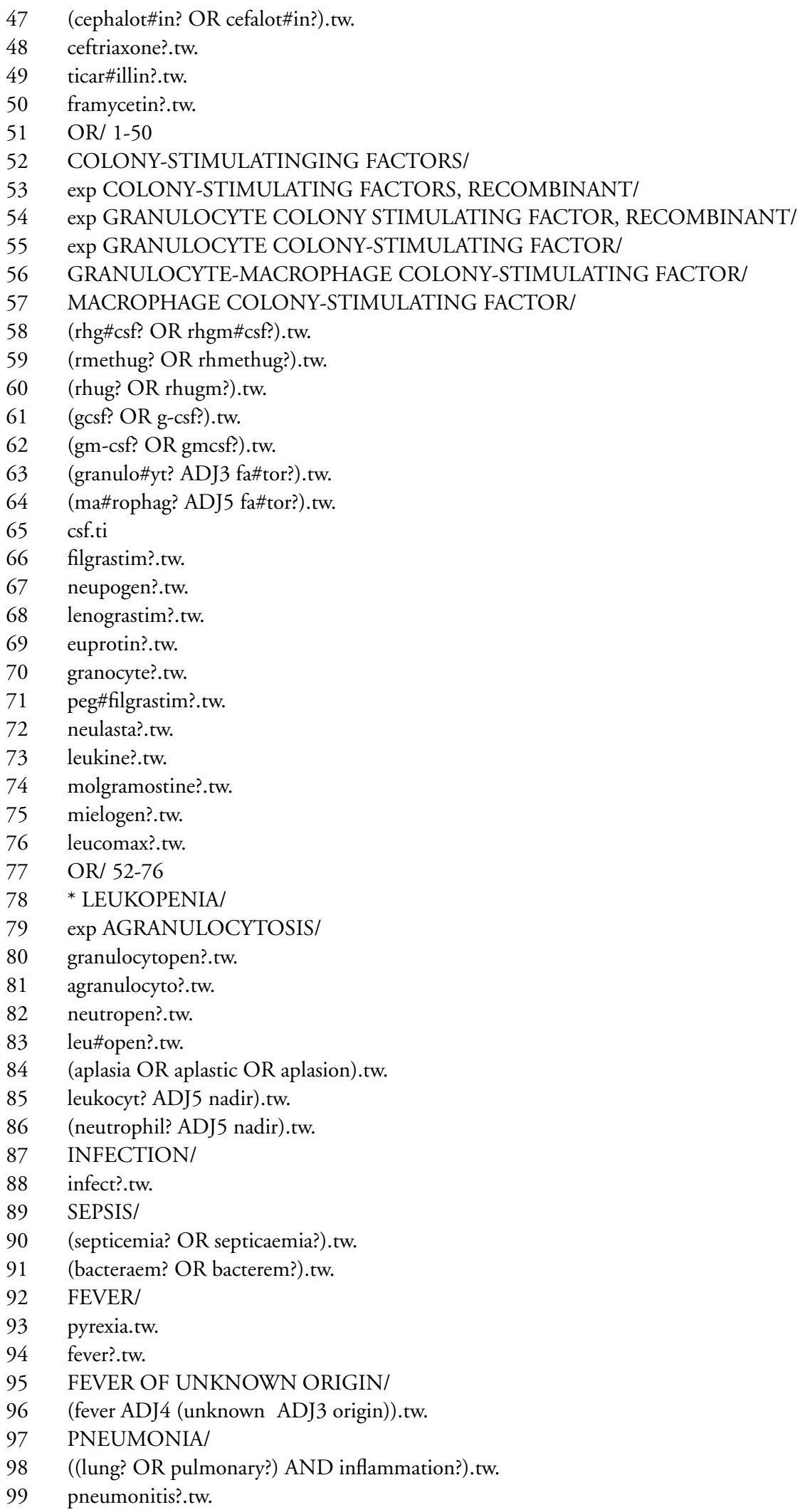

Prophylactic antibiotics or G-CSF for the prevention of infections and improvement of survival in cancer patients undergoing 


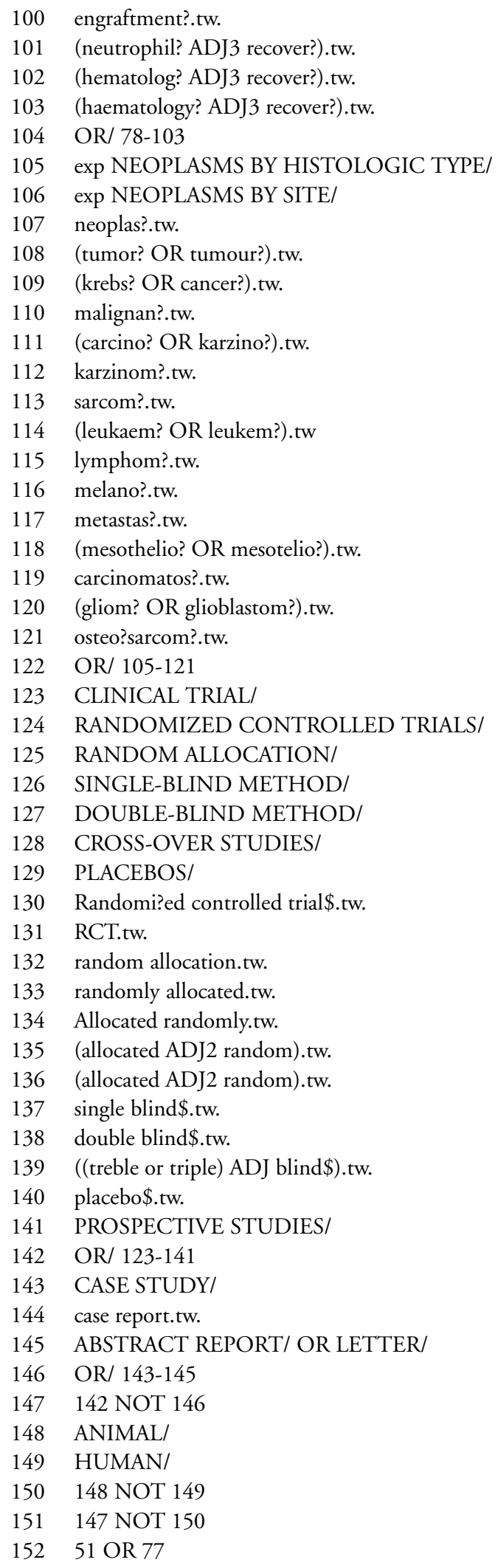

Prophylactic antibiotics or G-CSF for the prevention of infections and improvement of survival in cancer patients undergoing 


\section{Appendix 3. CENTRAL search strategy}

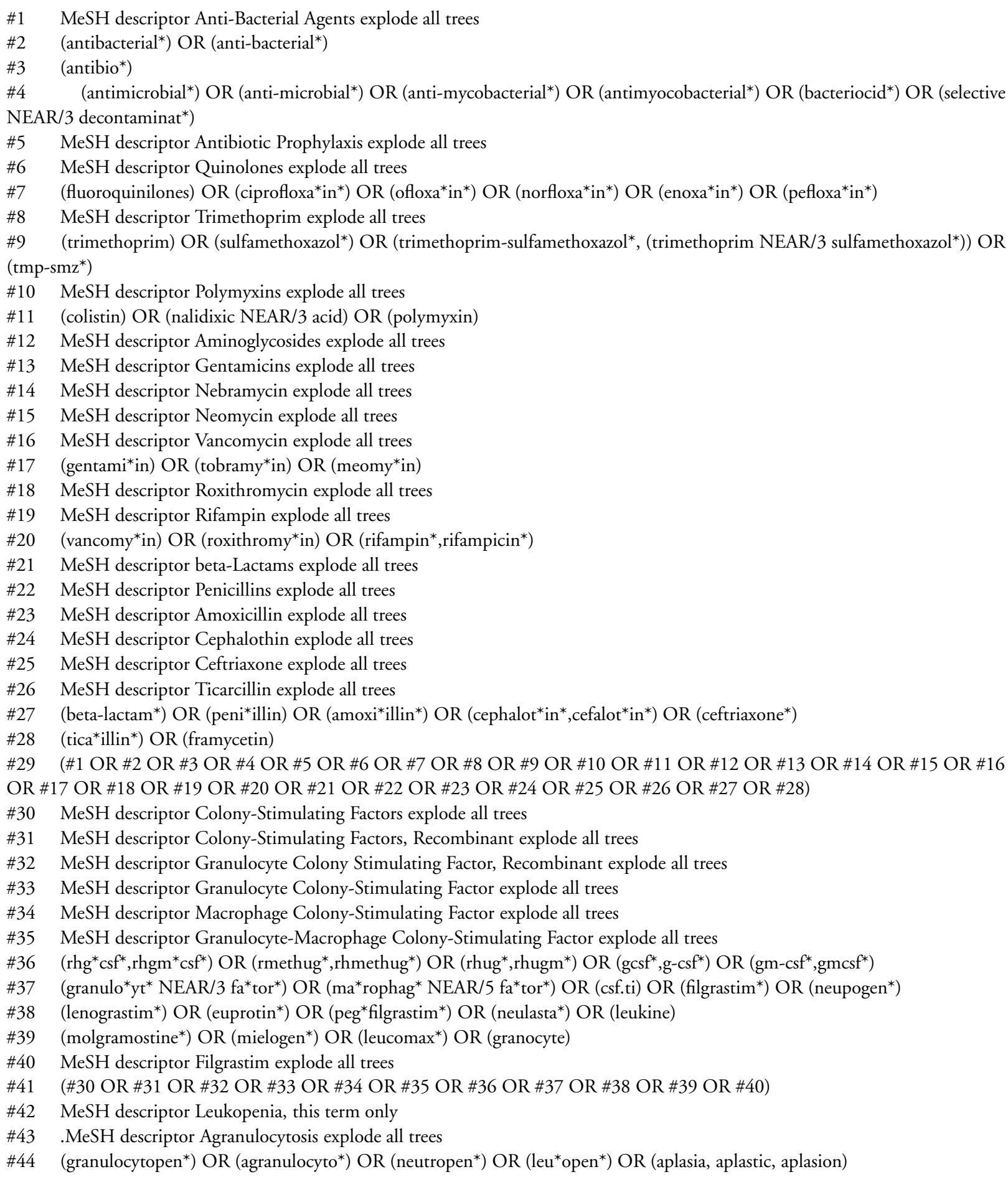

Prophylactic antibiotics or G-CSF for the prevention of infections and improvement of survival in cancer patients undergoing 
\#45 (leukocyt* NEAR/5 nadir) OR (neutrophil NEAR/5 nadir)

\#46 MeSH descriptor Infection explode all trees

\#47 (infect*)

\#48 MeSH descriptor Sepsis explode all trees

\#49 (septicemia, septicaemia) OR (bacteraem*, bacterem*) OR (fever*) OR (pyrexia) OR (fever NEAR/4 (unknown NEAR/3

origin))

\#50 MeSH descriptor Fever explode all trees

\#51 MeSH descriptor Fever of Unknown Origin, this term only

\#52 (pneumonia) OR (lung inflammation) OR (pulmonary inflammation) OR (pneumonitis)

\#53 (442 OR \#43 OR \#44 OR \#45 OR \#46 OR \#47 OR \#48 OR \#49 OR \#50 OR \#51 OR \#52)

\#54 MeSH descriptor Neoplasms by Histologic Type explode all trees

\#55 MeSH descriptor Neoplasms by Site explode all trees

\#56 (neoplas*) OR (krebs,cancer*) OR (malignan*)

\#57 (leukaem*,leukem*) OR (lymphom*) OR (melano*) OR (metastas*) OR (mesothelio*,mesotelio*)

\#58 (gliom,glioblastom*) OR (osteo* ${ }^{*}$ arcom*) OR (carcinomatos*) OR (blastom*) OR (neuroblastom* ${ }^{*}$ )

\#59 MeSH descriptor Pneumonia explode all trees

\#60 (\#54 OR \#55 OR \#56 OR \#57 OR \#58 OR \#59)

\#61 (\#53 OR \#59)

\#62 (\#29 AND \#41 AND \#61)

\section{H I S T O R Y}

Protocol first published: Issue 2, 2008

Review first published: Issue 1, 2009

\section{CONTRIBUTIONS OFAUTHORS}

Christine Herbst: protocol development, searching for trials, eligibility and quality assessment, data extraction and analysis, drafting of final review

Julia Bohlius: protocol development and clinical expertise

Holger Schulz: clinical expertise

Eva Kruse: protocol development

Nauman Frauke: protocol development, searching for trials, eligibility and quality assessment, data extraction and analysis

Ina Monsef: database search

Andreas Engert: clinical expertise and content input

\section{DECLARATIONSOF INTEREST}

None

Prophylactic antibiotics or G-CSF for the prevention of infections and improvement of survival in cancer patients undergoing 


\section{SOURCES OF SUPPORT}

\section{Internal sources}

- Köln Fortune, Germany.

Funding programme "Köln Fortune", Medical Faculty University of Cologne

\section{External sources}

- BMBF, Germany.

The Editorial Base is funded by Federal Ministry of Education and Research (BMBF) No : 01GH0501

- BMBF, Germany.

Project grant application NO 01KG0612, Federal Ministry of Education and Research (BMBF) 